\title{
Designing In Situ and Ex Situ Bulk Metallic Glass Composites via Spark Plasma Sintering in the Super Cooled Liquid State
}

James P. Kelly ${ }^{1,2}$, Seth M. Fuller ${ }^{2}$, Kyungah Seo $^{1}$, Ekaterina Novitskaya ${ }^{1}$, Veronica Eliasson ${ }^{3}$, Andrea M. Hodge ${ }^{3}$, and Olivia A. Graeve ${ }^{1,2, *}$

1 Department of Mechanical and Aerospace Engineering

University of California, San Diego

9500 Gilman Drive - MC 0411

La Jolla, CA 92093-0411

$2 \quad$ Kazuo Inamori School of Engineering

Alfred University

2 Pine Street, Alfred, NY 14802

3 Department of Aerospace and Mechanical Engineering

University of Southern California

3650 McClintock Ave. - OHE 430, Los Angeles, CA 90089-1453

\begin{abstract}
Crystallization inhibits metallic glass forming in the super cooled liquid state and can be avoided if sufficiently fast heating rates can be obtained, but becomes increasingly difficult for marginal glass formers. We propose that dynamic pressing can enhance formability, and demonstrate that density of an iron-based marginal glass forming alloy $\left(\mathrm{Fe}_{49.7} \mathrm{Cr}_{17.1} \mathrm{Mn}_{1.9} \mathrm{Mo}_{7.4} \mathrm{~W}_{1.6} \mathrm{~B}_{15.2} \mathrm{C}_{3.8} \mathrm{Si}_{2.4}\right)$ can be enhanced by coupling loading rate to fast heating rate during spark plasma sintering. We also describe the transformation kinetics for devitrification in a time-temperature-crystallinity diagram. The combination of coupled loading/fast heating and the time-temperature-crystallinity diagram define the processing requirements for obtaining a dense X-ray amorphous structure and can also be used to design a wide variety of dense in situ composites. Finally, we demonstrate that the design approach also applies to ex situ composites by adding microcrystalline $\mathrm{W}$ or $\mathrm{Ta}$, enabling systematic control of atomic-, nano-, and micro-structure. This multi-scale structure control of bulk metallic glass composites has implications for developing a fundamental understanding of structure-property relationships. We expect this general approach will be applicable to other bulk metallic glass composites, and especially beneficial for marginal glass formers that are otherwise difficult to process.
\end{abstract}

Keywords: Bulk metallic glass; spark plasma sintering; composite; microstructure; powder metallurgy; consolidation

* Corresponding author. Tel: (858) 246-0146, Fax: (858) 534-5698,

Email: ograeve@ucsd.edu, URL: http://graeve.ucsd.edu/ 


\section{Introduction}

Bulk metallic glass (BMG) and BMG-matrix composites are currently investigated for structural applications because of the potential to produce a material that is both strong and tough [1-6]. Pd- and Zr-based metallic glasses have now been produced with record-breaking combinations of strength $(\sim 1.6 \mathrm{GPa})$ and fracture toughness $\left(\sim 230 \mathrm{MPam}^{1 / 2}\right)$ [7]. Other advantages include superior elastic limit and higher resilience compared to their crystalline counterparts [8]. However, most BMGs are inherently brittle at room temperature, especially in tension, because of shear localization [9-12]. In situ crystalline composites (formed by devitrification) or ex situ crystalline composites (formed by addition of a second phase) can improve ductility. Common amorphous metal composite microstructures providing ductility include in situ nanocrystal composites [13-15], in situ dendrite composites [16, 17], and ex situ microcrystal composites [15, 18-20]. BMG alloys and composites can also have excellent fatigue resistance, depending on the specific alloy and processing conditions [21, 22]. Small processing variations can have large consequences on properties, but a comprehensive account of the processing-structure-property cycle and developing structural indicators to optimize mechanical properties of metallic glasses remain large barriers to widening the application potential of metallic glasses [23-25]. This work will describe the link between processing and structure of an Fe-based metallic glass, a first step in evaluating the processing-structureproperty cycle.

Fe-based metallic glasses and composites are of interest because they are less expensive than many other amorphous alloys [26], have yield strengths as high as $4 \mathrm{GPa}$ [27, 28], excellent magnetic properties [29-34], low coefficients of thermal expansion [35], excellent corrosion resistance [36-42], and can be used in a variety of applications [6, 43, 44]. Most Fe-based metallic glasses are based on an "80-20" rule, with approximately 80 at\% metals (M) and 20 at\% semimetals $(\mathrm{S})$ and/or nonmetals $(\mathrm{N})$, and is based on short range order that consists of distorted clusters with $\mathrm{M}:(\mathrm{N}+\mathrm{S})$ ratios close to 80:20 [45]. It is not surprising then that the $\mathrm{M}_{23} \mathrm{~N}_{6}$ crystalline phase is often a major devitrification product of Fe-based metallic glasses based on the stoichiometry of the crystalline phase relative to the 80:20 composition rule. The extent of covalent/ionic bonding and connectivity, controlled by chemistry, typically contributes to high strength and brittleness or lower strength and ductility [46, 47]. The $\mathrm{Fe}_{59} \mathrm{Cr}_{6} \mathrm{Mo}_{14} \mathrm{C}_{15} \mathrm{~B}_{6}$ amorphous alloy has a fracture strength of $4.4 \mathrm{GPa}$, a fracture toughness of $53 \mathrm{MPa} \cdot \mathrm{m}^{1 / 2}$, and limited ductility demonstrated by a plastic strain to failure of $0.8 \%$ [48]. The $\mathrm{Fe}_{50} \mathrm{Ni}_{30} \mathrm{P}_{14} \mathrm{~B}_{6}$ amorphous alloy has fracture strength of $2.7 \mathrm{GPa}$ and a plastic strain to failure of $5.2 \%$ in compression [49]. In situ dendritic Fe-based composites have been prepared that exhibit a fracture strength of $3 \mathrm{GPa}$ and strain to failure of $38 \%$ in compression [17]. Thus, several amorphous Fe-based alloys and composites with outstanding mechanical properties have been demonstrated.

Viscous forming of metallic glasses has substantial commercial potential and is anticipated to be transformative for the metals industry [23, 25]. Viscous forming of glass powder in the super cooled liquid state (i.e., between the glass transition and crystallization temperatures) expands the range of alloys that can be made in bulk form because critical cooling rate is decoupled from the forming process [50]. The most favorable processing trajectory for viscous forming of glass powder is to achieve full density prior to significant crystallization, because crystallization inhibits densification, and is facilitated by using fast heating rates to avoid nucleation [51]. Heating rates on the order of $10^{2}-10^{4} \mathrm{~K} / \mathrm{s}$ can be used to suppress 
crystallization in metallic glass alloys with critical casting thicknesses down to a few millimeters [52]. Heating rates up to $10^{3} \mathrm{~K} / \mathrm{s}$ can be obtained by the spark plasma sintering technique [5357], and can be used to avoid crystallization in many alloys to facilitate effective viscous forming. Applied stress can also facilitate densification of glass powders [51]. However, applied stress required to obtain dense amorphous metals by spark plasma sintering glass powder can be as high as $600 \mathrm{MPa}$, exceeding the strength of typical graphite tooling ( 150 MPa), so that more expensive tooling (e.g., $\mathrm{SiC}$ or $\mathrm{WC}$ ) is required and often limits sample size [33, 34, 58-64].

We propose that dynamic pressing during spark plasma sintering can be used as a parameter to enhance density. Viscous flow relieves shear stress and it is reasonable to assume that a time-dependent viscoelastic solution is required to describe the stress relaxation (i.e., the response of the material to a stress consists of a transient elastic strain and a time-dependent viscous flow strain) [51]. A viscoelastic type of response in metallic glasses is supported by the increasingly elastic response of metallic glasses by increasing loading rate during nanoindentation, where local stress can be high enough to cause flow [65]. The elastic strain is small for traditional viscous sintering processes, because there is ample time for relaxation to occur by viscous flow, and therefore a viscoelastic solution is not required in sintering models [51]. However, experiences in the oxide glass industry indicate this is not necessarily true for high-speed pressing of glasses, for which shear stress may build up from the high strain rate and inadequate rate of stress relaxation by viscous flow can cause fracture [66]. We propose that the most effective spark plasma sintering approach to enhance density by high-speed pressing is to couple the pressing operation to a fast heating rate because (i) shear stress will more effectively build up at low temperatures and be transferred to viscous flow at higher temperatures where flow is more effective, (ii) the effect will be realized before there is significant opportunity for crystallization that would inhibit densification.

SAM2X5 is an Fe-based alloy with nominal composition $\mathrm{Fe}_{49.7} \mathrm{Cr}_{17.1} \mathrm{Mn}_{1.9} \mathrm{Mo}_{7.4} \mathrm{~W}_{1.6} \mathrm{~B}_{15.2} \mathrm{C}_{3.8} \mathrm{Si}_{2.4}$. Previous attempts to consolidate SAM2X5 by spark plasma sintering resulted in $95-97 \%$ density and significant devitrification [67]. Our results show that dynamic pressing during fast heating can be used to achieve full density prior to devitrification. This is significant because SAM2X5 is a marginal glass former with a critical cooling rate of approximately $600 \mathrm{~K} / \mathrm{min}$ [40]. Devitrification of SAM2X5 can even be observed in feedstock powders produced by gas atomization [68], where thickness can be limited to sub-mm and cooling rates orders of magnitude higher than $600 \mathrm{~K} / \mathrm{min}$ are readily obtained. We also generate a time-temperature-crystallinity diagram to design in situ composites and demonstrate that ex situ particle additions do not affect the design strategy. Overall, we use a combination of dynamic pressing, the time-temperature crystallinity diagram, and ex situ particle additions to design and develop seven dense composites that demonstrate atomic-, nano-, and micro-structure control. The systematic control of structure will benefit developing a fundamental understanding of structure and properties with processing history. We expect our approach to be more widely applicable and particularly suitable for processing metallic glass alloys that have proven to be a challenge.

\section{Methods}

The as-received SAM2X5 metallic glass powders (Lot\# 04-191/-15 microns, The NanoSteel Company, Providence, RI) were sieved through a $15 \mu \mathrm{m}$ mesh screen. Powders of 
tungsten (W) and tantalum (Ta) were used and designated NW (99.95\%, $70 \mathrm{~nm}$, US Research Nanomaterials, Houston, TX), W powder designated MW1 (99.9\%, $12 \square \mathrm{m}$, Alfa Aesar, Ward Hill, MA), W powder designated MW2 (99.9\%, -325 mesh, Alfa Aesar, Ward Hill, MA), W powder designated MW3 (99.9\%, -100 mesh, Alfa Aesar, Ward Hill, MA), W powder designated MW4 (99.95\%, -200+325 mesh, Alfa Aesar, Ward Hill, MA), and tantalum (Ta) powder designated MT (99.98\%, -100 mesh, Alfa Aesar, Ward Hill, MA). Up to $40 \mathrm{vol} \% \mathrm{~W}$ or Ta powder was blended into the SAM2X5 powders. Composite samples were labeled with the SAM2X5 designation followed by a number corresponding to the vol\% $\mathrm{W}$ or Ta and the specific powder, that is, NW, MW1, MW2, MW3, MW4, or MT. The blending was done in a $125 \mathrm{~mL}$ high-density polyethylene wide-mouth bottle with a polypropylene cap containing $25 \mathrm{~g}$ of powder along with $80 \mathrm{~g}$ of cylindrical zirconia media $(\sim 8 \mathrm{~mm}$ height by $8 \mathrm{~mm}$ diameter). Powders were tumbled for $30 \mathrm{~min}$ at a speed that maximized cascading.

For SPS processing, a graphite die (Isocarb I85, Electrodes, Inc., Milford, CT) that produces cylindrical samples with diameter of $19 \mathrm{~mm}$ was lined with a graphite foil (2010A, CeraMaterials, Port Jervis, NY). A punch that was also lined with graphite foil was inserted into the die. An amount of powder that would result in a sintered sample of $0.6 \mathrm{~cm}^{3}$ was added to the graphite die, based on the density of SAM2X5 $\left(7.75 \mathrm{~g} / \mathrm{cm}^{3}\right)$ determined by helium pycnometry (AccuPyc II 1340, Micromeritics Instrument Corporation, Norcross, GA), the W density (19.25 $\left.\mathrm{cm}^{3}\right)$, the Ta density $\left(16.69 \mathrm{~g} / \mathrm{cm}^{3}\right)$, and the respective volume fractions for each composition desired. The die was rotated manually when the powders were poured into the die and lightly tapped to distribute the powders in the die evenly. Another graphite foil and punch were inserted into the die to complete the powder loading process. The powder mixture was pre-pressed with $20 \mathrm{MPa}$ of uniaxial stress. The die was wrapped with $10 \mathrm{~mm}$ PAN/graphite felt insulation (>99\% C, CeraMaterials, Port Jervis, NY) that had a $10 \mathrm{~mm}$ by $20 \mathrm{~mm}$ window cut out of the center for measuring temperature and was tied with carbon cord (18K, CeraMaterials, Port Jervis, NY).

The die was loaded into an SPS furnace (Model HP D25, FCT Systeme, Frankenblick, Germany) and subjected to a continuous vacuum atmosphere that was maintained at $5 \mathrm{~Pa}$. A uniaxial stress of $36 \mathrm{MPa}$ was applied to the sample prior to heating. Heating at constant power was applied until the measured temperature was $720 \mathrm{~K}$, after which pyrometer-controlled heating was applied. The pyrometer was focused on the outside surface of the die exposed by the window in the insulation. The applied heating rates were $50 \mathrm{~K} / \mathrm{min}, 100 \mathrm{~K} / \mathrm{min}, 200 \mathrm{~K} / \mathrm{min}, 300$ $\mathrm{K} / \mathrm{min}$, or $500 \mathrm{~K} / \mathrm{min}$ during pyrometer-controlled heating to the target temperature. The pressing force was also linearly increased so that the stress increased from a minimum pressure of $36 \mathrm{MPa}$ to a maximum pressure of $110 \mathrm{MPa}$ during pyrometer-controlled heating. Final temperatures were between $800 \mathrm{~K}$ and $970 \mathrm{~K}$ and maintained for an amount of time between 0 and 40 minutes. At the end of the heating cycle, the samples were cooled while linearly reducing the pressure from $110 \mathrm{MPa}$ to $10 \mathrm{MPa}$ over 10 minutes before releasing all pressure and removing the samples.

The SAM2X5 powder was characterized by differential scanning calorimetry (SDT 600, TA Instruments, New Castle, DE) using heating rates between $10 \mathrm{~K} / \mathrm{min}$ and $100 \mathrm{~K} / \mathrm{min}$ to a temperature of $1270 \mathrm{~K}$ in flowing argon. The powders and compacts were imaged using scanning electron microscopy (SEM) (FEI ${ }^{\mathrm{TM}}$ Quanta 200F, FEI Company, Hillsboro, OR). Where applicable, energy dispersive spectra of selected areas in the microstructures were collected from 0 to $12 \mathrm{keV}$. Thin foil sample preparation and initial imaging was performed by transmission electron microscopy (TEM) by Analysis Services Lab (Azle, TX) and also imaged 
using a Tecnai ${ }^{\mathrm{TM}}$ TEM (G2 Sphera, FEI Company, Hillsboro, OR). X-ray diffraction (XRD) (D2 Phaser, Bruker AXS, Madison, WI) was performed by scanning from 20 to 70 degrees $2 \theta$ using a step size of 0.05 degrees $2 \theta$ and a minimum count time of $3 \mathrm{~s}$. Thermal expansion was measured using a dilatometer (Dil 402 PC, Netzsch, Selb, Germany) over the temperature range of 370 to $870 \mathrm{~K}$. Bulk density was measured by the immersion method.

\section{Results and Discussions}

\subsection{SAM2X5 Powder}

First we evaluate the SAM2X5 powder, an essential step for obtaining bulk materials of the highest quality possible [69]. A back-scattered electron image of the SAM2X5 powder in the as-received state is illustrated in Figure 1(a). The particles are mostly spherical in morphology, but there are a few instances of elongated particles and fibers, a few of which are marked in Figure 1(a) as examples. This combination of morphologies is common in powders prepared by gas atomization $[20,59,70]$. The powders also contain a small fraction of larger particles, one of which is illustrated in the back-scattered electron image of Figure 1(b). This particular particle was polished to provide a cross section that reveals an internal pore and a surrounding crystalline region, which is common among most of the larger particles present in the batch. The crystalline nature of the larger SAM2X5 particles has previously been reported [40] and is a reminder that each particle has its own thermal history based on the ability to quench particles of a given size during gas atomization. Certainly, if the larger particles are not removed prior to consolidation, they end up in the final microstructure. Figure 1(c) is an example of a microstructure (after consolidation) containing what was originally one of the larger particles, with the original particle boundary outlined in white. The image was taken at a higher magnification to demonstrate the presence of crystals within the boundary that are not observed outside of the boundary. Based on observation of many cross-sectioned particles, the crystalline regions are likely present before consolidation instead of being a product of the consolidation process. Figure 1(d) is an image of a microstructure containing soft inclusions. The assessment that these inclusions are soft is based on the striations observed in the microstructure, which are remnant scratches from early grinding and polishing steps resulting from a faster grinding rate of the softer phase. Secondary electron images are not shown, but indicate that the soft phase is recessed on the polished surface when compared to the matrix. Figure 1(e) is an energy dispersive spectrum collected from the soft inclusions. The primary peak found just below 1 $\mathrm{keV}$ indicates that the inclusions are Ni-based. The composition of SAM2X5 does not contain $\mathrm{Ni}$, thus, the Ni must be an impurity phase introduced during gas atomization, possibly from the nozzles used during the process, or subsequent handling processes of the material.

The majority of the larger particles (crystalline, with internal pores, and/or ductile particles) are removed by sieving the powder through a $15 \mu \mathrm{m}$ mesh screen. However, Figure 1(f) is a back-scattered electron image of another type of inclusion that demonstrates that the sieving process does not remove all anomalous particles because a small fraction of them are small enough in size that they pass through the sieve. The energy dispersive spectrum for this phase is given Figure $\mathbf{1}(\mathbf{g})$, and demonstrates a primary signal from Mo. Furthermore, the energy dispersive spectrum of the inclusion matrix phase (not shown) is depleted in Mo compared to the energy dispersive spectrum of the bulk SAM2X5 (not shown). Finally, Figure 1(h) is a back-scattered electron image demonstrating the presence of internal pores contained within original particles that were also small enough to pass through the $15 \mu \mathrm{m}$ sieve. All these 
anomalies are rare, especially after implementing the sieving process, but possibly important because they can be the source for brittle failure, pitting corrosion, and fatigue crack initiation.

\subsection{Enhanced Consolidation of SAM2X5 Powder with Dynamic Pressing}

As we described in the introduction, a combination of fast pressing and heating can enhance viscous forming of metallic glasses. Figure 2 schematically demonstrates the coupled pressing/heating approach we used. The initial temperature at the beginning of pyrometercontrolled heating and where significant densification begins, $T_{i}$, is labeled in Figure 2(a) and corresponds to $720 \mathrm{~K}$. The change in temperature during pyrometer-controlled heating is the difference between the sintering temperature, $\mathrm{T}_{\mathrm{s}}$, and the initial temperature (i.e., $\Delta \mathrm{T}=\mathrm{T}_{\mathrm{s}}-720$ $\mathrm{K})$. Three examples of $\mathrm{T}_{\mathrm{s}}$ are labeled in Figure 2(a) and correspond to points $\mathrm{A}, \mathrm{B}$, and $\mathrm{C}$. The heating rate to points $A$ and $B$ is labeled $\sigma_{A, B}$ in Figure 2(a). Likewise, the heating rate to point $\mathrm{C}$ is labeled $\sigma_{\mathrm{C}}$, which is greater than $\sigma_{\mathrm{A}, \mathrm{B}}$. The dynamic pressing is performed so that the maximum applied stress, $\sigma_{f}$, is reached at the same time as $T_{s}$. The initial applied stress at the beginning of pyrometer-controlled heating, $\sigma_{i}$, is labeled in Figure 2(b) and corresponds to 36 $\mathrm{MPa}$. The maximum applied stress is $110 \mathrm{MPa}$, labeled in Figure 2(b), and the change in applied stress during heating to $\mathrm{T}_{\mathrm{s}}$ is the difference between the maximum applied stress and the initial applied stress (i.e., $\Delta \sigma=74 \mathrm{MPa}$ ). The arrow in Figure 2(b) from point $\mathrm{A}^{\prime}$ to point B' demonstrates that reducing $\mathrm{T}_{\mathrm{s}}$ from point $\mathrm{A}$ to point $\mathrm{B}$ decreases the time over which the applied stress is changed. Likewise, the arrow from point $B$ ' to C' demonstrates that increasing the heating rate also decreases the time over which the applied stress is changed. Reducing the time over which the applied stress is changed increases the applied stress rate, do/dt, which is demonstrated by comparing $\mathrm{d} \sigma / \mathrm{dt}_{\mathrm{A}}, \mathrm{d} \sigma / \mathrm{dt}_{\mathrm{B}}$, and $\mathrm{d} \sigma / \mathrm{dt}_{\mathrm{C}}$, in Figure 2(b). Equation (1) is a generic description of the applied stress rate in $\mathrm{MPa} / \mathrm{min}$ as a function of the controlling parameters $\phi$ and $\mathrm{T}_{\mathrm{s}}$ before and after making the substitutions for $\Delta \sigma$ and $\Delta \mathrm{T}$ described in the text above:

$$
\frac{\mathrm{d}}{\mathrm{dt}}=\frac{\cdot}{\mathrm{T}}=\frac{74}{\left(\mathrm{~T}_{\mathrm{s}} 720\right)}
$$

Figure 3(a) demonstrates the effect of $\phi$ on displacement rate of the pressing ram during heating when using the approach outlined in Figure 2, in which the ram displacement rate is directly related to the strain rate [52]. The maximum ram displacement rate is approximately 1 $\mathrm{mm} / \mathrm{min}$ using a heating rate of $50 \mathrm{~K} / \mathrm{min}$ and is approximately $10 \mathrm{~mm} / \mathrm{min}$ at $300 \mathrm{~K} / \mathrm{min}$. Thus, the maximum strain rate is expected to increase approximately one order of magnitude by changing the heating rate from $50 \mathrm{~K} / \mathrm{min}$ to $300 \mathrm{~K} / \mathrm{min}$. The enhanced strain rate with faster heating rate is observed over the entire temperature range for which displacement occurs ( 720$930 \mathrm{~K})$, also causing an apparent onset for significant displacement at lower temperatures that we suspect contributes to the buildup of shear stress. There is a significant decrease in displacement rate that occurs near $850 \mathrm{~K}$ irrespective of the heating rate, corresponding to the glass transition temperature of SAM2X5 [40, 67], after which the displacement rate becomes essentially constant (both features are marked with arrows in Figure 3(a)). The data indicates that much of the shear stress developed below $850 \mathrm{~K}$ is quickly released at the glass transition temperature by viscous flow. Another feature observed in Figure 3(a) is that the constant displacement rate at temperatures above the glass transition temperature is also increased at least an order of 
magnitude with increasing heating rate from $50 \mathrm{~K} / \mathrm{min}$ to $300 \mathrm{~K} / \mathrm{min}$, indicating an increased shear rate and more effective viscous flow. The increased shear rate above the glass transition temperature could be a result of maintaining a higher resolved shear stress with faster heating, a reduced viscosity due to a reduction in devitrification and corresponding viscous drag, or a combination of both mechanisms. The two features observed in Figure 3(a), the buildup of shear stress that is released at the glass transition temperature and an increased shear rate above the glass transition temperature, are the key features supporting the concept that fast pressing during heating enhances densification.

Equation 1 indicates that reducing $\mathrm{T}_{\mathrm{s}}$ will have the same effect as increasing $\phi$ if dynamic pressing and corresponding effects on strain rate control densification. Figure 3(b) illustrates the SAM2X5 compact density is strongly correlated to the applied stress rate when using the dynamic pressing strategy outlined in Figure 2. The applied stress rate was changed either by varying $\mathrm{T}_{\mathrm{s}}$ at a constant heating rate of $100 \mathrm{~K} / \mathrm{min}$ (red diamonds in Figure 3(b)) or by changing $\phi$ for three different constant $\mathrm{T}_{\mathrm{s}}$ values (black squares, green triangles, and blue circles in Figure 3(b)), according to the schematic demonstrated in Figure 2 and previously described. Reducing $\mathrm{T}_{\mathrm{s}}$ to generate the data represented by red diamonds in Figure 3(b) enhanced density because of the increase in $\mathrm{d} \sigma / \mathrm{dt}$. Reducing sintering temperature ordinarily inhibits viscous sintering because of higher viscosity, but the density was inhibited by increasing temperature instead because the applied stress rate dominates the densification behavior. The dotted line in Figure 3(b) corresponds to the SAM2X5 powder density of $7.75 \mathrm{~g} / \mathrm{cm}^{3}$. The solid curve in Figure 3(b) is a phenomenological equation fit to all of the data demonstrating that the compact density correlates well to the applied stress rate irrespective of whether $\phi$ or $T_{s}$ is used to vary the applied stress rate. The coefficient of correlation for the fitted line is 0.88 , indicating a reasonably good fit considering the difficulty in accurately controlling temperature for the fast heating rates that were used. We rely on an empirical phenomenological approach because no physical basis has been developed to describe our approach, and would be difficult to develop without prior knowledge of the frequency-dependent complex viscosity measurements required to verify a viscoelastic solution. It is worth noting that the viscosity is expected to have an exponential form so that densification, which is inversely related to viscosity for viscous sintering, is expected to have a logarithmic form. The equation for the fit is given by:

$$
=0.24 \cdot \ln \left(\frac{\mathrm{d}}{\mathrm{dt}}\right)+6.48
$$

Equation (2) shows that in the absence of dynamic pressing (i.e., for an infinitesimal low strain rate), the density would be $6.48 \mathrm{~g} / \mathrm{cm}^{3}$, neglecting other thermal kinetic effects. Full density can be achieved by using an applied stress rate of $200 \mathrm{MPa} / \mathrm{min}$, and corresponds to a $20 \%$ enhancement in density as a direct result of dynamic pressing.

Substituting Equation (1) into Equation (2) and solving for the heating rate results in:

$$
=\exp \left(\frac{6.48}{0.24}\right) \cdot \frac{\mathrm{T}_{\mathrm{s}} 720}{74}
$$


Equation (3) is now in a form that can be used to determine the heating rate necessary for a specified target density for a given sintering temperature. To obtain a target density equivalent to the SAM2X5 powder, one substitutes $7.75 \mathrm{~g} / \mathrm{cm}^{3}$ into Equation 3, resulting in:

$$
=\exp \left(\frac{7.756 .48}{0.24}\right) \cdot \frac{\mathrm{T}_{\mathrm{s}} 720}{74}=2.68 \cdot\left(\mathrm{T}_{\mathrm{s}} \quad 720\right)
$$

Equation (4) is a general approximation to the densification behavior of the samples, because it will not produce fully dense samples if structural relaxation or crystallization processes change the theoretical density. A series of equations similar to Equation (4) could be generated for a variety of densities substituted into Equation (3). From this, we have constructed a density map (Figure 3(c)), which includes densities higher than that of the powder to incorporate possible effects of relaxation or devitrification. Figure 3(c) can be used to guide the selection of an appropriate heating rate to obtain a fully dense material for a desired processing temperature. We present the data in this way because the desired processing temperature may change based on the level of devitrification desired to create in situ composites, which will be described in the next section.

\subsection{Devitrification of SAM2X5}

Deciphering the structural evolution in amorphous metals, in order to establish causal links between key local structure and macroscopic properties, remains a major challenge [23, 24]. Establishing causal links can be masked by inadequate characterization of structure with processing history, which can produce large property variations for the same material. Thus, there is a need to find easily measurable structural indicators that can be used to track the extent of structure evolution. In this section, we address this issue by first looking at the devitrification of SAM2X5 powder to identify relevant devitrification temperatures and then use this information to design SPS experiments for which the final temperature and holding time are varied. From this, the evolution of structural indicators is summarized in the form of a timetemperature-crystallinity diagram that is directly representative of the consolidation process [67].

Differential scanning calorimetry (DSC) curves collected using heating rates of 10, 20, and $100 \mathrm{~K} / \mathrm{min}$ are given in Figure 4. The inset diagrams in Figure 4 exhibit truncated scales to provide more detailed information. Four distinct exothermic events associated with the devitrification process are observed. For the curve corresponding to a heating rate of $20 \mathrm{~K} / \mathrm{min}$, we have labeled the local maximum in heat flow for these exothermic events $T_{x 1}, T_{x 2}, T_{x 3}$, and $\mathrm{T}_{\mathrm{x} 4}$. A heating rate of $20 \mathrm{~K} / \mathrm{min}$ is initially used because it was the slowest heating rate where information was not lost. In general, slow heating rates provide better temperature accuracy, but decrease the intensity of the heat signal. The heat signal from $T_{x 1}$ is weak enough that it is lost when using a heating rate of $10 \mathrm{~K} / \mathrm{min}$. The signals for $\mathrm{T}_{\mathrm{x} 2}, \mathrm{~T}_{\mathrm{x} 3}$, and $\mathrm{T}_{\mathrm{x} 4}$, can be distinguished as individual peaks for low heating rates. However, there is significant overlap between the $T_{x 2}$ and $\mathrm{T}_{\mathrm{x} 3}$ peaks for fast heating rates, which is demonstrated by the curve corresponding to a heating rate of $100 \mathrm{~K} / \mathrm{min}$ for which $\mathrm{T}_{\mathrm{x} 2}$ is only observed as a shoulder on the left side of the $\mathrm{T}_{\mathrm{x} 3}$ peak.

The onset and peak temperatures $\left(\mathrm{T}_{\mathrm{oi}}\right.$ and $\mathrm{T}_{\mathrm{xi}}$ ) of the exothermic events at $20 \mathrm{~K} / \mathrm{min}$ are as follows. $T_{01}$ and $T_{x 1}$ are $810 \mathrm{~K}$ and $830 \mathrm{~K}$, respectively, $\mathrm{T}_{02}$ and $\mathrm{T}_{\mathrm{x} 2}$ are $900 \mathrm{~K}$ and $930 \mathrm{~K}$, respectively, $T_{03}$ and $T_{x 3}$ are $950 \mathrm{~K}$ and $970 \mathrm{~K}$, respectively, and $\mathrm{T}_{\mathrm{o} 4}$ and $\mathrm{T}_{\mathrm{x} 4}$ are $1040 \mathrm{~K}$ and $1080 \mathrm{~K}$, respectively. The $\mathrm{T}_{\mathrm{x} 1}$ observed in this study is slightly lower than the $850 \mathrm{~K}$ glass transition temperature, $\mathrm{T}_{\mathrm{g}}$, for SAM2X5 [40,67]. Thus, it appears that the minor exothermic 
event associated with $T_{x 1}$ is a sub- $T_{g}$ phenomenon. It is unclear what the $T_{x 1}$ event is, but it could involve structural relaxation, phase separation, quasi-crystalline formation, growth of subcritical or quenched-in nuclei, or new nuclei formation and growth. These processes have been discussed elsewhere [2, 26, 50, 71-83], and could all produce an exothermic heat signal. Crystallization in other Fe-based systems has been found to occur below the reported crystallization temperatures, and even up to $40^{\circ} \mathrm{C}$ below $\mathrm{T}_{\mathrm{g}}[84,85]$. Minor phases detected during early stages of SAM2X5 devitrification include those based on $\mathrm{Cr}_{2} \mathrm{~B}, \mathrm{WC}, \mathrm{Fe}_{23} \mathrm{C}_{6}$, and $\alpha$ $\mathrm{Fe}$ phases [40]. Hirata et al. [86] have reported an $\mathrm{Fe}_{23} \mathrm{~B}_{6}$ quasi-crystalline structure that forms prior to crystallization of the $\mathrm{Fe}_{23} \mathrm{~B}_{6}$ phase in an Fe-based metallic glass. Phase separation has been observed in a similar Fe-based amorphous metal alloy [87], which can precede and facilitate devitrification. Again, the exact mechanism in this alloy is unknown and cannot be obtained from the current data.

The $\mathrm{T}_{\mathrm{x} 2}, \mathrm{~T}_{\mathrm{x} 3}$, and $\mathrm{T}_{\mathrm{x} 4}$ temperatures found in this work are consistent with the three-stage crystallization process for SAM2X5 previously reported by Branagan et al. [68]. The major devitrification products of SAM2X5 identified in Branagan's study were $\alpha$-Fe with a space group of $\mathrm{Im} 3 \mathrm{~m}, \gamma$-Fe with a space group of $\mathrm{Fm} 3 \mathrm{~m}$, and $\mathrm{Fe}_{23}(\mathrm{~B}, \mathrm{C})_{6}$ with a space group of $\mathrm{Fm} 3 \mathrm{~m}$. $\mathrm{T}_{\mathrm{x} 1}$ was most likely not observed in Branagan's study because it was masked by the $10 \mathrm{~K} / \mathrm{min}$ heating rate that was used for the thermal analysis, as we previously described, and demonstrates the advantage of TGA using multiple heating rates. Figure 5 is a plot used to estimate the activation energies of the four exothermic events via the Kissinger method [88]. Linear fits to the data are also included and have coefficients of correlation of $0.95,0.98,0.96$, and 0.98 , for $\mathrm{T}_{\mathrm{x} 1}, \mathrm{~T}_{\mathrm{x} 2}, \mathrm{~T}_{\mathrm{x} 3}$, and $\mathrm{T}_{\mathrm{x} 4}$, respectively, indicating excellent fits. Also included are the slopes of these linear fits, $\mathrm{m}$, and the corresponding activation energies, $\mathrm{E}_{\mathrm{a}}$, with values of $220 \mathrm{~kJ} / \mathrm{mol}, 370$ $\mathrm{kJ} / \mathrm{mol}, 690 \mathrm{~kJ} / \mathrm{mol}$, and $490 \mathrm{~kJ} / \mathrm{mol}$, for $\mathrm{T}_{\mathrm{x} 1}, \mathrm{~T}_{\mathrm{x} 2}, \mathrm{~T}_{\mathrm{x} 3}$, and $\mathrm{T}_{\mathrm{x} 4}$, respectively. The physical meaning of the thermal events will be further explored by X-ray diffraction.

Recently, we demonstrated the concept of a time-temperature-crystallinity (TTC) diagram to approximate devitrification kinetics during SPS processing of metallic glasses in lieu of more tedious methods [67]. A TTC diagram is generated using measurements of average crystallite sizes of compacts prepared by SPS as a function of temperature and time. The TTC diagram is easy to obtain and directly representative of the processing environment and average bulk compact structure, and while it is limited by the XRD detection limit, it is an empirical guide for designing in situ composites on the nanostructure level. Here we will demonstrate that the TTC diagram is also useful for tracking short- and medium-range ordering without having to define the atomistic details. Our previously developed TTC diagrams [67] were constructed based on crystallite size estimates using X-ray line broadening of the primary XRD peaks, which limits applicability when there is peak overlap. In this study, we use a similar concept, but refrain from calculating and reporting average crystallite sizes and report full-width at halfmaximum (FWHM) to describe X-ray peak evolution, recognizing that overlapping peaks can also produce broadening and result in inaccurate size estimates.

We collected XRD patterns for samples sintered at temperatures around $\mathrm{T}_{\mathrm{x} 1}, \mathrm{~T}_{\mathrm{x} 2}$, and $\mathrm{T}_{\mathrm{x} 3}$, then measured the FWHM of the primary diffraction peak. As a reminder, the onset and peak temperatures $\left(\mathrm{T}_{\mathrm{oi}}\right.$ and $\mathrm{T}_{\mathrm{xi}}$ ) of the exothermic events in SAM2X5 observed using DSC at a heating rate of $20 \mathrm{~K} / \mathrm{min}$ are $\mathrm{T}_{\mathrm{o} 1}=810 \mathrm{~K}, \mathrm{~T}_{\mathrm{x} 1}=830 \mathrm{~K}, \mathrm{~T}_{\mathrm{o} 2}=900 \mathrm{~K}, \mathrm{~T}_{\mathrm{x} 2}=930 \mathrm{~K}, \mathrm{~T}_{\mathrm{o} 3}=950 \mathrm{~K}, \mathrm{~T}_{\mathrm{x} 3}=970$ $\mathrm{K}, \mathrm{T}_{\mathrm{o} 4}=1040 \mathrm{~K}$, and $\mathrm{T}_{\mathrm{x} 4}=1080 \mathrm{~K}$. These temperatures were only used to define the experimental range for SPS experiments because it is not possible to make a direct comparison between the two sets of temperatures; the outside temperature measured during SPS is not the 
same as the internal sample temperature [89]. Furthermore, the detection limits of the DSC and XRD techniques used for characterization are different [26]. Figure 6 contains representative XRD patterns (Figure 6(a)-(c)) for a variety of temperatures and times that demonstrate the structural indicators we have found and the resulting TTC diagram (Figure 6(d)) that describes the evolution of these indicators with respect to temperature and time.

Figure 6(a) contains XRD patterns for the SAM2X5 powder, a compact with sintering temperature $\left(\mathrm{T}_{\mathrm{s}}\right)$ that demonstrates the first structural transformation $\left(\mathrm{T}_{\mathrm{x} 1}\right)$, and a compact demonstrating the onset of the second structural transformation $\left(\mathrm{T}_{\mathrm{o} 2}\right)$. The XRD peak of the powder is labeled " 1 " and is a single broad peak that has a FWHM of 6.5. The XRD pattern for $\mathrm{T}_{\mathrm{s}}=820 \mathrm{~K}$ demonstrates two peaks for the first structural transformation, labeled " 2 " and " 3 ". The peak labeled " 2 " is narrower than the primary diffraction peak of the powder (FWHM = 5.7). Narrowing of the diffuse diffraction peak during the initial stages of devitrification has been reported previously $[67,87]$ and can be used as a structural indicator for short-to-medium range ordering during relaxation and prior to crystallization. The peak labeled " 3 " corresponds to a diffraction signal that emerges at approximately 68 degrees $2 \theta$, indicating some extent of order with a characteristic d-spacing of approximately $1.4 \AA$. Although an interesting observation that may have important implications on elucidating atomistic mechanisms, we do not use this feature as a structural indicator because it is weak, not persistent, and so not of current interest. The XRD pattern for $\mathrm{T}_{\mathrm{s}}=880 \mathrm{~K}$ illustrates the peak corresponding to the onset of the second structural transformation, which is labeled " 4 ". This peak occurs at approximately 48 degrees $2 \theta$ and corresponds to the emergence of an $(\mathrm{Fe}, \mathrm{Cr}, \mathrm{Mn}, \mathrm{Mo}, \mathrm{W})_{23}(\mathrm{~B}, \mathrm{C}, \mathrm{Si})_{6}$ phase (i.e., a solid solution phase based on $\mathrm{Fe}_{23} \mathrm{~B}_{6}$ ). The FWHM of the primary XRD peak is further reduced to 2.6 at the onset of this transition. The FWHM of the primary diffraction peak from 6.5 to 2.6 can be used as an indicator of the first structural transformation, until the emergence of a diffraction peak at 48 degrees $2 \theta$, indicating the onset of the second structural transformation.

Figure 6(b) contains XRD patterns spanning the onset of $(\mathrm{Fe}, \mathrm{Cr}, \mathrm{Mn}, \mathrm{Mo}, \mathrm{W})_{23}(\mathrm{~B}, \mathrm{C}, \mathrm{Si})_{6}$ formation (at $\mathrm{T}_{\mathrm{s}}=880 \mathrm{~K}$ ) to the onset of the third structural transformation $\left(\right.$ at $\left.\mathrm{T}_{\mathrm{s}}=960 \mathrm{~K}\right)$. The peak intensities for the $(\mathrm{Fe}, \mathrm{Cr}, \mathrm{Mn}, \mathrm{Mo}, \mathrm{W})_{23}(\mathrm{~B}, \mathrm{C}, \mathrm{Si})_{6}$ phase increase at an intermediate $\mathrm{T}_{\mathrm{s}}$ of 910 $\mathrm{K}$, but no new phases are observed. The FWHM is 2.6 for this sample and negligibly different compared to the sample sintered at $880 \mathrm{~K}$. The peaks for the transformation beginning at $960 \mathrm{~K}$ are numbered " 5 " and " 6 ", and correspond to the primary diffraction peak and the emergence of a peak belonging to a new phase. The new phase is a $(\mathrm{Fe}, \mathrm{Cr}, \mathrm{Mn}, \mathrm{Mo}, \mathrm{W})_{7}(\mathrm{~B}, \mathrm{C}, \mathrm{Si})_{3}$ phase (i.e., based on $\mathrm{Fe}_{7} \mathrm{C}_{3}$ ) and the primary diffraction peak now overlaps with the peak for the $(\mathrm{Fe}, \mathrm{Cr}, \mathrm{Mn}, \mathrm{Mo}, \mathrm{W})_{23}(\mathrm{~B}, \mathrm{C}, \mathrm{Si})_{6}$ phase. The FWHM of the combined peak is 2.7. Thus, the FWHM was negligibly different from $\mathrm{T}_{\mathrm{s}}$ of 880 to $960 \mathrm{~K}$ and will not be a good structural indicator for the second transformation. We will revisit this point when interpreting the TTC diagram.

Figure 6(c) illustrates XRD patterns for samples that have been sintered at $960 \mathrm{~K}$ for progressively longer times. Within 5 minutes at $960 \mathrm{~K}$, we find that what was once the primary diffraction peak separates into two peaks, corresponding to two distinct phases, the $(\mathrm{Fe}, \mathrm{Cr}, \mathrm{Mn}, \mathrm{Mo}, \mathrm{W})_{7}(\mathrm{~B}, \mathrm{C}, \mathrm{Si})_{3}$ phase that was already observed and an $\alpha-\mathrm{Fe}$ phase, labeled peak "7". With increasing time, the peak intensity of the $\alpha$-Fe phase increases. The FWHM of the $\alpha-$ Fe peak is 1.0 after 5 minutes and further reduces to 0.7 after 20 minutes, indicating that FWHM can be used as a structural indicator for evolution of this phase once the peak is sufficiently separated from the primary diffraction peak so that a measurement can be made. 
The corresponding TTC diagram describing the structural evolution with temperature and time is given in Figure $\mathbf{6}(\mathbf{d})$, generated from samples sintered at a heating rate of $100 \mathrm{~K} / \mathrm{min}$. The bottom portion of the diagram has contours describing the first structural transformation (i.e., the FWHM of structural indicator "2" in Figure 6(a)). The bottom white curve corresponds to the onset of the second structural transformation (i.e., the appearance of structural indicator "4" in Figure 6(a)). Between the two white curves, the FWHM of the primary diffraction peak was monitored, but found to change insignificantly. The upper white curve corresponds to the onset of the third structural transformation (i.e., the appearance of the structural indicators " 5 " and " 6 " in Figure 6(b)). The contours in the upper region of the diagram correspond to the FWHM of structural indicator " 5 " in Figure 6(b) when there is peak overlap, or structural indicator " 7 " in Figure 6(c) when the peak is sufficiently separated. The points in the diagram correspond to samples prepared at those time-temperature conditions. The diamonds correspond to samples within the first structural transformation region, open circles correspond to the second transformation region, closed circles correspond to the third transformation region, and half filled circles correspond to boundaries between transformation regions. The two solid curves fits can be described by logarithmic fits. The upper boundary is:

$$
\mathrm{T}_{\mathrm{U}}=17.6 \ln \mathrm{t}_{\mathrm{U}}+965
$$

based on five data points and has a coefficient of correlation greater than 0.99 . We estimate that the lower boundary can be described by:

$$
\mathrm{T}_{\mathrm{L}}=15.5 \ln \mathrm{t}_{\mathrm{L}}+887
$$

assuming the same form as Equation (5). The dotted line extends the fit for the lower boundary based on Equation (6). Contour lines of the FWHM values (labeled in white) demonstrate that the FWHM decreases with increasing temperature or time during the first transformation, changes negligibly during the second transformation, and decreases with increasing temperature or time during the third transformation. The FWHM contours appear to follow a similar form as Equation (5) and Equation (6) for the first and third transformations. Although the FWHM is not a sufficient indicator to track structural evolution for the second transformation, it is proposed that the structural evolution within this range will follow a similar trend as the remainder of the diagram (i.e., a form similar to Equation (5), Equation (6), and the contours). Equation (5) and Equation (6) can practically be translated onto each other, indicating that shifting either curve may be an appropriate approximation of the time-temperature structure evolution within the entire diagram.

Another feature included in Figure 6(d) is the $T_{o i}$ and $T_{x i}$ temperatures determined from DSC. Thermal events are usually observed at lower temperatures by TEM and DSC, as compared to XRD, because of better detection limits of the former techniques [26]. However, this is not the case in Figure 6(d). $T_{02}$ and $T_{x 2}$ established by DSC were 900 and $930 \mathrm{~K}$, respectively, but $\mathrm{T}_{\mathrm{O} 2}$ determined by constructing the TTC diagram with XRD results corresponds to the lower boundary and is represented by Equation (6), corresponding to temperatures less than $880 \mathrm{~K}$ and depending on time. This is most likely because the temperature measured by SPS is lower than the actual sample temperature [89]. Thus, the DSC results are not directly 
applicable to the SPS process, further demonstrating the significance of using a TTC diagram for tracking structural evolution and understanding how processing history influences properties.

\subsection{Designing In Situ and Ex Situ Composites}

We have now described two tools that can be used to design in situ composites. The TTC diagram in Figure 6(d) can be used to select temperature and time for designing the type and level of crystallinity and Figure 3(c) can be used to select an appropriate heating rate to ensure that full density is obtained. We will demonstrate the development of two in situ composites using this approach that correspond to either the first transformation or the second transformation. We will also explore the applicability and limits of applying this approach to $e x$ situ composites.

The first in situ composite is designated SAM2X5-630. The target sintering temperature was selected to be higher than the second structural transformation according to Figure 6(d), where $(\mathrm{Fe}, \mathrm{Cr}, \mathrm{Mn}, \mathrm{Mo}, \mathrm{W})_{23}(\mathrm{~B}, \mathrm{C}, \mathrm{Si})_{6}$ crystallization is observed by XRD. A heating rate of 500 $\mathrm{K} / \mathrm{min}$ to a sintering temperature of $900 \mathrm{~K}\left(630^{\circ} \mathrm{C}\right)$, and without any hold time at temperature, was selected using Figure 3(c) to obtain a target density equivalent to the SAM2X5 powder (7.8 $\left.\mathrm{g} / \mathrm{cm}^{3}\right)$. The density was then confirmed using the immersion technique. A second in situ composite designated SAM2X5-600 was generated using similar conditions, but by reducing the sintering temperature to $870 \mathrm{~K}\left(600^{\circ} \mathrm{C}\right)$, which is just below the sintering temperature at which $(\mathrm{Fe}, \mathrm{Cr}, \mathrm{Mn}, \mathrm{Mo}, \mathrm{W})_{23}(\mathrm{~B}, \mathrm{C}, \mathrm{Si})_{6}$ crystallization is observed, resulting in an X-ray amorphous sample. The density of the SAM2X5-600 composite was $7.7 \mathrm{~g} / \mathrm{cm}^{3}$, negligibly different from the SAM2X5-630 sample. The slight difference in density can be attributed to the different levels of devitrification.

Representative microstructures of the SAM2X5-630 and SAM2X5-600 in situ composites are demonstrated in Figure 7. The SEM image of the SAM2X5-630 compact in Figure 7(a) demonstrates that there are distinct boundaries where original particle surfaces have bonded together and submicron pores present at some of the triple points. The TEM image in Figure 7(b) for the same sample demonstrates greater microstructure detail at one of the triple points. The boundaries are actually a discontinuous set of nanometer-scale pores that only appear as a continuous line at lower magnifications. Thus, the sample does not have continuous grain boundaries and can be expected to maintain superior corrosion resistance compared to a fully crystalline state [36-42]. The speckled appearance in the bulk of each grain corresponds to the nanocrystals formed during devitirifcation. Figure 7(c) demonstrates that the SAM2X5-600 has a similar microstructure, but the triple point porosity is generally smaller. Better densification for SAM2X5-600 is expected based on the application of a similar heating rate and lower temperature (see Figure 3(c)). A triple point in the SAM2X5-600 composite viewed with TEM is demonstrated in Figure 7(d), and is similar in character to that of the SAM2X5-630 sample demonstrated in Figure 7(b). The speckling within the grains of the SAM2X5-600 sample indicates that devitrification occurs, but is obviously below the detection limit of XRD. Other researchers have also observed nanocrystals by TEM in materials that were amorphous according to XRD [90]. It is also recognized that TEM sample preparation can induce oxidation, crystallization, and surface reconstruction as an artifact that makes it difficult to perform quantitative analysis [91-94]. However, less speckling in Figure 7(d) when compared to Figure 7(b) suggests fewer crystals that are a result of processing and not an artifact of sample preparation since they were prepared in an identical way. Current characterization techniques do not provide very good resolution and limit structural analysis of metallic glasses [95]. 
Nevertheless, DSC and XRD remain the easiest techniques for characterizing devitrification as a function of thermal history, whereas TEM provides supporting details about local structure. For example, we observe two different crystal morphologies with TEM. The single set of lattice fringes embedded in the amorphous matrix in Figure 7(e) demonstrates a single isolated nanocrystal. At least four different orientations for lattice fringes are observed in Figure 7(f) and demonstrate a cluster of crystals embedded in an amorphous matrix. Nieh et al. [96] describe that these two types of morphologies respond differently to deformation. Thus, in addition to the different local structures, the distribution of the structures is likely to be important.

We have also determined the baseline quasi-static mechanical properties of SAM2X5600 using nano-, micro-, and bulk-scale characterization techniques [97]. Continuing to characterize these materials will facilitate developing a comprehensive understanding of structure-property relationships for purposes of tailoring properties for specific applications. As an example, we recently investigated the response of the SAM2X5-600 and SAM2X5-630 in situ composites to shock wave compression [98], the first report of its kind for amorphous steels. The results indicate that the very small difference in structure, resulting from processing on either side of the second transformation boundary, can enhance the Hugoniot Elastic Limit by $37 \%$, up to $12 \mathrm{GPa}$, and is the highest for any $\mathrm{BMG}$ reported thus far.

The utility of the TTC diagram and Figure 3(c) to design in situ composites has now been demonstrated. Herein, we explore the limits for designing ex situ composites using the same approach. That is, we use the same parameters used to develop the SAM2X5-630 composite, but with a variety of crystalline powders added to the amorphous metal powder. Figure 8 demonstrates that particle size [99-114] is an important consideration for developing $e x$ situ composites. Figure 8(a) illustrates the presence of $\mathrm{W}$ nanoparticle agglomerates in the microstructure with as little as $4 \mathrm{vol} \%$. Poorly sintered agglomerates at the boundaries are undesirable because they concentrate stress, which can degrade mechanical properties. Even if the nanoparticles could be perfectly dispersed along the boundaries, the nanoparticles would saturate the boundaries at relatively low volume fractions because of the much larger specific surface area of the nanopowder relative to the SAM2X5 powder. Larger volume fractions can be added if the particle size is increased because of the decrease in specific surface area. However, the addition of larger sizes may amplify the stress field in the vicinity of the particle due to thermal expansion mismatch strains. Figure 8(b) demonstrates cracking in the SAM2X5 matrix if $\mathrm{W}$ particles are too large, for example. Thus, there is a need to optimize the effect of particle sizes for a given volume fraction of particle additions, a topic we explore next.

Figure 9 demonstrates compact density (Figure 9(a)), phases (Figure 9(b)), and microstructure (Figure 9(c)) of our ex situ composites. The solid line in Figure 9(a) is the theoretical density of the ex situ composites containing different volume fractions of $\mathrm{W}$ (generated using SAM2X5 density of $7.8 \mathrm{~g} / \mathrm{cm}^{3}$, W density of $19.3 \mathrm{~g} / \mathrm{cm}^{3}$, and a rule of mixtures). The dotted curves are second order polynomial fits, each having a coefficient of correlation greater than 0.99 . There is a systematic deviation from theoretical density as a function of $\mathrm{W}$ particle size and volume percentage. Smaller W particles cause the density to deviate from theoretical density at lower volume fractions and to a greater extent at larger volume fractions than for larger particles. XRD patterns of ex situ composites are given in Figure 9(b), which includes an inset with truncated axes to provide more detail. Aside from the $\mathrm{XRD}$ peaks for $\mathrm{W}$ that increase with increasing volume fraction and a corresponding decrease in SAM2X5 peak intensities, there is no discernible difference in the XRD patterns, indicating that 
devitrification is unaffected by $\mathrm{W}$ additions (small or large sizes and volume fractions). Figure 9(c) is a TEM image at a SAM2X5/W interface in an ex situ composite and confirms that the SAM2X5 matrix is similar to that demonstrated in Figure 8(b) and that there is good bonding between the SAM2X5 and $\mathrm{W}$.

The SAM2X5 structure appears to be negligibly affected by $\mathrm{W}$ additions so that the thermal expansion coefficient of the SAM2X5-630 composite can be applied to analysis of the ex situ composites. The measured linear thermal expansion coefficient of the SAM2X5-630 composite was $6.6 \mathrm{~K}^{-1}$, which is similar to other Fe-based amorphous alloys [35]. The linear thermal expansion coefficient of $\mathrm{W}$ is $4.6 \mathrm{~K}^{-1}$ [115]. The $\mathrm{W}$ inclusions will generate a tensile stress in the SAM2X5 matrix phase and the SAM2X5 will generate compressive stress in W during cooling from the sintering temperature. Thus, if the $\mathrm{W}$ size is large enough it will generate enough tensile stress to exceed the strength of the SAM2X5 matrix phase and cause crack initiation and propagation. Thus, smaller $\mathrm{W}$ particles are preferred for lower volume fractions to limit tensile stress in the SAM2X5 matrix, and larger sizes are preferred for obtaining higher volume fractions.

Five dense ex situ composite microstructures with good uniformity are demonstrated in Figure 10, four having $\mathrm{W}$ as the compositing phase (Figure 10(a)-(d)) and one having Ta (Figure 10(f)). The crystalline particle sizes embedded in the SAM2X5 matrix were optimized for the particle size effects we previously described. The inset in Figure 10(a) demonstrates greater microstructure detail of the SAM2X5-2NW composite. The $\mathrm{W}$ particle sizes in the SAM2X5-10MW1 composite (Figure 10(b)) are smaller than the $\mathrm{W}$ sizes in the SAM2X520MW2 composite (Figure 10(c)). However, there are W regions in the SAM2X5-10MW1 composite that are as large as those in the SAM2X5-20MW2 composite, which is demonstrated by the insets in Figure 10(b) and Figure 10(c), respectively. The large $W$ regions in the SAM2X5-10MW1 composite are polycrystalline, indicating that some extent of W agglomeration is tolerated and that the $\mathrm{W}$ agglomerates sinter to high density. Sintering of W particles is also observed in the other compacts, which is obvious in the insets of Figure 10(c) and Figure 10(d) for the SAM2X5-20MW2 and SAM2X5-30MW3 compacts, respectively. The TEM image of the SAM2X5-30MW3 in Figure 10(e) demonstrates W-W polycrystalline interfaces more clearly than in the SEM images. The sintering of $\mathrm{W}$ agglomerates is unexpected because $\mathrm{W}$ is a refractory metal typically sintered at temperatures from 1823 to $2173 \mathrm{~K}$ and difficult to sinter to full density even at these temperatures [116-120]. It is possible that a reaction between SAM2X5 and $\mathrm{W}$ facilitates $\mathrm{W}-\mathrm{W}$ particle sintering [69]. Alternatively, or synergistically, atomistic simulations [122] indicate that pre-melting of $\mathrm{W}$ surface layers gives mechanistic behavior similar to viscous flow. Thus, the dynamic pressing strategy used in this work to improve viscous flow of SAM2X 5 could also be responsible for the unexpected sintering of $\mathrm{W}$ particles at a modest temperature of $900 \mathrm{~K}$. The microstructure of the SAM2X5-30MT composite in Figure 10(f) contains crystalline Ta particles. The Ta is distributed with good uniformity throughout the SAM2X5-30MT composite and was designed so that comparisons could be made to the SAM2X5-30MW3 composite. The linear thermal expansion coefficient of Ta is $6.4 \mathrm{~K}^{-1}$ [115], closer to that of the SAM2X5 composite matrix, and would produce lower tensile stress in the matrix when compared to $\mathrm{W}$.

An optimum addition of $\mathrm{W}$ has been shown to improve the yield strength and induce ductility in Zr-based BMGs [123] and Ni-based BMGs [124]. In both reports, the ductility is attributed to the popular notion that the crystalline $\mathrm{W}$ phase restricts shear band propagation and promotes the generation of multiple shear bands in the matrix phase. Conner et al. [123] used a 
melt infiltration process, which is not suitable for marginal glass formers like SAM2X5 because this alloy cannot be cooled fast enough to prevent devitrification in large parts. Furthermore, the type of reinforcement phase is limited by the high temperatures required for melt infiltration, which is less of a limitation when using a fast viscous forming technique. Conner et al. also highlight the importance of unequal thermal expansion coefficients that cause thermal strains. The addition of some tensile stress in the matrix can be beneficial because it directs cracks towards the reinforcement phase where crack tip blunting can occur and because stress concentration at the front of a shear band triggers the formation of additional shear bands when the original shear band meets an obstacle. Thus, our study of particle size effects to control residual stress and the use of reinforcement phases with different coefficients of thermal expansion compared to the SAM2X5 matrix are highly relevant to optimizing mechanical properties. Xie et al. [124] used an applied stress of $600 \mathrm{MPa}$ to incorporate $\mathrm{W}$ (2-3 $\mu \mathrm{m}$ in size) into a Ni-based BMG by viscous forming, and reported an optimum volume fraction of $5 \% \mathrm{~W}$ to enhance both yield strength and ductility. However, additional $\mathrm{W}$ was also found to decrease the density below $99 \%$ of theoretical, consistent with our results presented in Figure 9(a). Thus, it is impossible to tell whether or not the decline in strength and ductility above $5 \% \mathrm{~W}$ was a result of increased $\mathrm{W}$ or pores that are stress concentrators. Our study demonstrates how to optimize particle loading so that the root cause can be established unequivocally.

\section{Conclusions}

In this study, we have demonstrated a viscous forming strategy for the consolidation of iron-based metallic glass powders using spark plasma sintering. The strategy uses dynamic pressing during rapid heating and provides independent control of densification (with heating rate) and devitrification (with temperature and time). We propose that dynamic pressing is an alternative strategy to the application of high stresses during processing and it can be used to develop other amorphous metals of interest. It can be particularly useful for marginal glass formers that are otherwise difficult to process. The microstructures we present demonstrate the ability to produce dense bulk metallic glass composites with varying levels of relaxation, devitrification, secondary phases, secondary phase particle sizes, and secondary phase volume fractions. Thus, our approach offers several degrees of freedom for microstructural design and control. In particular, using the concept of a time-temperature-crystallinity diagram, we prepared composites of SAM2X5 $\left(\mathrm{Fe}_{49.7} \mathrm{Cr}_{17.1} \mathrm{Mn}_{1.9} \mathrm{Mo}_{7.4} \mathrm{~W}_{1.6} \mathrm{~B}_{15.2} \mathrm{C}_{3.8} \mathrm{Si}_{2.4}\right)$ with varying levels of devitrification, as well as with the incorporation of tungsten and tantalum particles.

This systematic control of structure enables the study of structure-property correlations without density having a confounding effect. That is, all samples are dense and the property response of the samples is only associated with inherent material behavior and not variable porosity. Processing at temperatures and times corresponding to structural relaxation can be used to study the effect of atomic ordering on mechanical properties. Processing at temperatures and times corresponding to partial devitrification can be used to study interactions between nanocrystals and the amorphous phase. The addition of different types of microcrystals and sizes can also be used to study the interactions between crystals and amorphous phases. If the interactions between crystals and an amorphous phase are understood, then it may be possible to intentionally use crystals to probe an amorphous phase and be combined with atomistic simulations to develop fundamental structure-property theory for metallic glasses. 


\section{References}

1. M.M. Trexler, N.N. Thadhani, Prog. Mater. Sci. 55 (2010) 759.

2. J. Eckert, J. Das, S. Pauly, C. Duhamel, J. Mater. Res. 22 (2007) 285.

3. $\quad$ E.S. Park, D.H. Kim, Met. Mater. Int. 11 (2005) 19.

4. $\quad$ W.L. Johnson, Mater. Res. Soc. Bull. 24 (1999) 42.

5. J. Eckert, U. Kühn, J. Das, S. Scudino, N. Radtke, Adv. Eng. Mater. 7 (2005) 587.

6. J.F. Löffler, Intermetallics 11 (2003) 529.

7. J. Xu, E. Ma, J. Mater. Res. 29 (2014) 14.

8. $\quad$ M.F. Ashby, A.L. Greer, Scripta Mater. 54 (2006) 321.

9. $\quad$ A.L. Greer, Y.Q. Cheng, E. Ma, Mater. Sci. Eng. R 74 (2013) 71.

10. $\quad$ Y. Yang, C.T. Liu, J. Mater. Sci. 47 (2012) 55.

11. M.L. Falk, J.S. Langer, Annu. Rev. Condens. Matter Phys. 2 (2011) 353.

12. Y. Zhang, Mater. Sci. Technol. 24 (2008) 379.

13. K. Hajlaoui, A.R. Yavari, A. LeMoulec, W.J. Botta, G. Vaughan, J. Das, A.L. Greer, A. Kvick, J. Non-Cryst. Solids 353 (2007) 327.

14. M. Calin, J. Eckert, L. Schultz, Scripta Mater. 48 (2003) 653.

15. A. Inoue, C. Fan, J. Saida, T. Zhang, Sci. Technol. Adv. Mater. 1 (2000) 73.

16. J. Qiao, J. Mater. Sci. Technol. 29 (2013) 685.

17. S.F. Guo, L. Liu, N. Li, Y. Li, Scripta Mater. 62 (2010) 329.

18. J.S.C. Jang, J.Y. Ciou, T.H. Hung, J.C. Huang, X.H. Du, Appl. Phys. Lett. 92 (2008) 011930.

19. J.K. Lee, H.J. Kim, T.S. Kim, Y.C. Kim, J.C. Bae, J. Alloys Compd. 434-435 (2007) 336.

20. C.K. Kim, H.S. Lee, S.Y. Shin, J.C. Lee, D.H. Kim, S. Lee, Mater. Sci. Eng. A 406 (2005) 293.

21. G.Y. Wang, P.K. Liaw, M.L. Morrison, Intermetallics 17 (2009) 579.

22. K. Boopathy, D.C. Hofmann, W.L. Johnson, U. Ramamurty, J. Mater. Res. 24 (2009) 3611.

23. Editorial, Nature Mater. 14 (2015) 541.

24. E. Ma, Nature Mater. 14 (2015) 547.

25. Interview, Nature Mater. 14 (2015) 553.

26. W.H. Wang, C. Dong, C.H. Shek, Mater. Sci. Eng. R 44 (2004) 45.

27. A. Inoue, B.L. Shen, C.T. Chang, Intermetallics 14 (2006) 936.

28. X.J. Gu, S.J. Poon, G.J. Shiflet. J. Mater. Res. 22 (2007) 344.

29. H.R. Lashgari, D. Chu, S. Xie, H. Sun, M. Ferry, S. Li, J. Non-Cryst. Solids 391 (2014) 61.

30. S. Bhattacharya, E.A. Lass, S.J. Poon, G.J. Shiflet, M. Rawlings, M. Daniil, M.A. Willard, J. Appl. Phys. 111 (2012) 063906.

31. R. Hasegawa, D. Azuma, J. Magn. Mang. Mater. 320 (2008) 2451.

32. P. Tiberto, M. Baricco, E. Olivetti, R. Piccin, Adv. Eng. Mater. 9 (2007) 468.

33. B. Shen, H. Kimura, A. Inoue, Mater. Sci. Forum 475-479 (2005) 3397.

34. B. Shen, A. Inoue, J. Mater. Res. 18 (2003) 2115.

35. M. Hatate, J.S. Garitaonandia, K. Suzuki, J. Appl. Phys. 103 (2008) 07B909.

36. J. Farmer, J.-S. Choi, C. Saw, J. Haslam, D. Day, P. Hailey, T. Lian, R. Rebak, J. Perepezko, J. Payer, D. Branagan, B. Beardsley, A. D’Amato, L. Aprigliano, Metall. Mater. Trans. A 40 (2009) 1289. 
37. Y.-F. Wu, W.-C. Chiang, J.-K. Wu, Mater. Lett. 62 (2008) 1554.

38. R.B. Rebak, S.D. Day, T. Lian, P.D. Hailey, J.C. Farmer, Metall. Mater. Trans. A 39 (2008) 225.

39. J.R. Scully, A. Gebert, J.H. Payer, J. Mater. Res. (2007) 302.

40. J.C. Farmer, J.J. Haslam, S.D. Day, T. Lian, C.K. Saw, P.D. Hailey, J.-S. Choi, R.B. Rebak, N. Yang, J.H. Payer, J.H. Perepezko, K. Hildal, E.J. Lavernia, L. Ajdelsztajn, D.J. Branagan, E.J. Buffa, L.F. Aprigliano, J. Mater. Res. 22 (2007) 2297.

41. D. Szewieczek, A. Baron, J. Mater. Proc. Technol. 157-158 (2004) 442.

42. M. Naka, K. Hashimoto, T. Masumoto, J. Non-Cryst. Solids 29 (1978) 61.

43. $\quad$ E. Axinte, Mater. Design 35 (2012) 518.

44. S. Hao, M. Widom, D.S. Scholl, J. Phys.: Condens. Matter 21 (2009) 115402.

45. C. Suryanarayana, A. Inoue, Intl. Mater. Rev. 58 (2013) 131.

46. X.J. Gu, S.J. Poon, G.J. Shiflet, M. Widom, Acta Mater. 56 (2008) 88.

47. Y.Q. Cheng, E. Ma, Prog. Mater. Sci. 56 (2011) 379.

48. J.J. Lewandowski, X.J. Gu, A.S. Nouri, S.J. Poon, G.J. Shiflet, Appl. Phys. Lett. 92 (2008) 091918.

49. $\quad$ L. Zhang, X. Ma, Q. Li, J. Zhang, Y. Dong, C. Chang, J. Alloys Compd. 608 (2014) 79.

50. J. Schroers, Adv. Mater. 22 (2010) 1566.

51. M.N. Rahaman, Ceramic Processing and Sintering, $2^{\text {nd }}$ Edition, Marcel Dekker, Inc., New York, 2003.

52. W.L. Johnson, G. Kaltenboeck, M.D. Demetriou, J.P. Schramm, X. Liu, K. Samwer, C.P. Kim, D.C. Hofmann, Science 332 (2011) 828.

53. J.P. Kelly, O.A. Graeve, JOM 67 (2015) 29.

54. K. Sinha, B. Pearson, S.R. Casolco, J.E. Garay, O.A. Graeve, J. Am. Ceram. Soc. 92 (2009) 2504.

55. B.M. Clark, J.P. Kelly, O.A. Graeve, Mater. Res. Soc. Symp. Proc. 1485 (2013) 9.

56. B.M. Clark, J.P. Kelly, O.A. Graeve, Mater. Res. Soc. Symp. Proc. 1373 (2012) 7.

57. O.A. Graeve, H. Singh, A. Clifton, Ceram. Trans. 194 (2006) 209.

58. Q. Li, G. Wang, X. Song, L. Fan, W. Hu, F. Xiao, Q. Yang, M. Ma, J. Zhang, R. Liu, J. Mater. Process Technol. 209 (2009) 3285.

59. J.C. Kim, H.J. Ryu, J.S. Kim, B.K. Kim, Y.J. Kim, H.J. Kim, J. Alloys Compd. 483 (2009) 28.

60. J.K. Lee, H.J. Kim, T.S. Kim, S.Y. Shin, Y.C. Kim, J.C. Bae, J. Mater. Proc. Technol. 187-188 (2007) 801.

61. P.P. Choi, J.S. Kim, O.T.H. Nguyen, D.H. Kwon, Y.S. Kwon, J.C. Kim, Mater. Sci. Eng. A 449-451 (2007) 1119.

62. P.P. Choi, J.S. Kim, O.T.H. Nguyen, Y.S. Kwon, Mater. Lett. 61 (2007) 4591.

63. T.-K. Kim, J.-K. Lee, H.-J. Kim, J.-C. Bae, Mater. Sci. Eng. A 402 (2005) 228.

64. K. Ozaki, T. Nishio, A. Matsumoto, K. Kobayashi, Mater. Sci. Eng. A 375-377 (2004) 857.

65. B.C. Wei, L.C. Zhang, T.H. Zhang, D.M. Xing, J. Das, J. Eckert, J. Mater. Res. 22 (2007) 258.

66. A.K. Varshneya, Fundamentals of Inorganic Glasses, Academic Press, Inc., San Diego, 1994.

67. O.A. Graeve, M.S. Saterlie, R. Kanakala, S. Diaz de la Torre, J.C. Farmer, Scripta Mater. 69 (2013) 143. 
68. D.J. Branagan, W.D. Swank, B.E. Meacham, Metall. Mater. Trans. A 40 (2009) 1306.

69. J.P. Kelly, O.A. Graeve, Effect of powder characteristics on nanosintering, in: R.H.R. Castro, K. Van Benthem (Eds.), Sintering Mechanisms of Conventional Nanodensification and Field Assisted Processes, Springer Science, New York, 2013.

70. O.A. Graeve, R. Kanakala, L. Kaufman, K. Sinha, W. Enhai, B. Pearson, G. RojasGeorge, J.C. Farmer, Mater. Lett. 62 (2008) 2988.

71. D.V. Louzguine-Luzgin, J. Alloys Compd. 586 (2014) S2.

72. D.H. Kim, W.T. Kim, E.S. Park, N. Mattern, J. Eckert, Prog. Mater. Sci. 58 (2013) 1103.

73. G.E. Abrosimova, Phys.-Usp. 54 (2011) 1227.

74. M. Yan, P. Yu, K.B. Kim, J.K. Lee, G.B. Schaffer, M. Qian, Scripta Mater. 62 (2010) 266.

75. S. Bose, A. Puthucode, R. Banerjee, P. Ayyub, J. Phys.: Condens. Matter 21 (2009) 285305.

76. J.H. Perepezko, J. Hamann, R.J. Hebert, H. Rösner, G. Wilde, Mater. Sci. Eng. A 449451 (2007) 84.

77. N. Mattern, J. Non-Cryst. Solids 353 (2007) 1723.

78. K.F. Kelton, J. Metastab. Nanocryst. 24-25 (2005) 25.

79. A.L. Greer, J. Metastab. Nanocryst. 24-25 (2005) 19.

80. F. Faupel, W. Frank, M.-P. Macht, H. Mehrer, V. Naundorf, K. Rätzke, H.R. Schober, S.K. Sharma, H. Teichler, Rev. Mod. Phys. 75 (2003) 237.

81. U. Ramamurty, M.L. Lee, J. Basu, Y. Li, Scripta Mater. 47 (2002) 107.

82. W.L. Johnson, Curr. Opin. Solid St. M. 1 (1996) 383.

83. K.F. Kelton, T.K. Croat, A.K. Gangopadhyay, L.-Q. Xing, A.L. Greer, M. Weyland, X. Li, K. Rajan, J. Non-Cryst. Solids 317 (2003) 71.

84. A. Hirata, Y. Hirotsu, E. Matsubara, Intermetallics 17 (2009) 796.

85. N. Nagendra, U. Ramamurty, T.T. Goh, Y. Li, Acta Mater. 48 (2000) 2603.

86. A. Hirata, Y. Hirotsu, K. Amiya, N. Nishiyama, A. Inoue, Phys. Rev. B 80 (2009) 140201(R).

87. H.M. Ha, J.H. Payer, Metall. Mater. Trans. A 40 (2009) 2009.

88. H.E. Kissinger, Anal. Chem. 29 (1957) 1702.

89. J.P. Kelly, O.A. Graeve, Acta Mater. 84 (2015) 472.

90. M.S. El-Eskandarany, M. Omori, A. Inoue, J. Mater. Res. 20 (2005) 2845.

91. L.-Y. Chen, Y.-W. Zeng, Q.-P. Cao, J. Mater. Res. 24 (2009) 3116.

92. M.W. Chen, A. Inoue, W. Zhang, T. Sakurai, Phys. Rev. Lett. 96 (2006) 245502.

93. H.J. Chang, E.S. Park, Y.C. Kim, D.H. Kim, Mater. Sci. Eng. A 406 (2005) 119.

94. B.B. Sun, Y.B. Wang, J. Wen, H. Yang, M.L. Sui, J.Q. Wang, E. Ma, Scripta Mater. 53 (2005) 805.

95. Z.H. Stachurski, Mater. 4 (2011) 1564.

96. T.G. Nieh, J. Wadsworth, C.T. Liu, T. Ohkubo, Y. Hirotsu, Acta Mater. 49 (2001) 2887.

97. G.R. Khanolkar, M.B. Rauls, J.P. Kelly, O.A. Graeve, A.M. Hodge, V. Eliasson, Sci. Rep. (2015) accepted.

98. T.Q. Phan, J.P. Kelly, M.E. Kassner, V. Eliasson, O.A. Graeve, A.M. Hodge, J. Mater. Sci. (2015) accepted.

99. J.T. Cahill, J.N. Ruppert, B. Wallis, Y. Liu, O.A. Graeve, Langmuir, 30 (2014) 5585.

100. C.I. Vargas-Consuelos, K. Seo, M. Camacho-Lopez, O.A. Graeve, J. Phys. Chem. C, 118 (2014) 9531. 
101. O.A. Graeve, H. Fathi, J.P. Kelly, M.S. Saterlie, K. Sinha, G. Rojas-George, R. Kanakala, D.R. Brown, E.A. Lopez, J. Colloid Interface Sci. 407 (2013) 302.

102. B. Higgins, O.A. Graeve, D.D. Edwards, J. Am. Ceram. Soc. 96 (2013) 2402.

103. M.S. Saterlie, H. Sahin, B. Kavlicoglu, Y. Liu, O.A. Graeve, Chem. Mater. 24 (2012) 3299.

104. H. Fathi, J.P. Kelly, V.R. Vasquez, O.A. Graeve, Langmuir 28 (2012) 9267.

105. R. Kanakala, R. Escudero, G. Rojas-George, M. Ramisetty, O.A. Graeve, ACS Appl. Mater. Interfaces 3 (2011) 1093.

106. M.S. Saterlie, H. Sahin, B. Kavlicoglu, Y. Liu, O.A. Graeve, Nanoscale Res. Lett. 6 (2011) 217.

107. J.P. Kelly, O.A. Graeve, J. Am. Ceram. Soc. 94 (2011) 1706.

108. J.P. Kelly, R. Kanakala, O.A. Graeve, J. Am. Ceram. Soc. 93 (2010) 3035.

109. R. Kanakala, G. Rojas-George, O.A. Graeve, J. Am. Ceram. Soc. 93 (2010) 3136.

110. O.A. Graeve, A. Madadi, R. Kanakala, K. Sinha, Metall. Mater. Trans. A 41 (2010) 2691.

111. O.A. Graeve, R. Kanakala, A. Madadi, B.C. Williams, K.C. Glass, Biomaterials 31 (2010) 4259.

112. K. Sinha, B. Kavlicoglu, Y. Liu, F. Gordaninejad, O.A. Graeve, J. Appl. Phys. 106 (2009) 064307.

113. O.A. Graeve, K. Sinha, Int. J. Mod. Phys. B 21 (2007) 4774.

114. O.A. Graeve, S. Varma, G. Rojas-George, D. Brown, E.A. Lopez, J. Am. Ceram. Soc. 89 (2006) 926.

115. J.F. Shackelford, W. Alexander (Eds.), Materials Science and Engineering Handbook, third ed., CRC Press, Boca Raton, FL, 2001.

116. E. Autissier, M. Richou, L. Minier, F. Naimi, G. Pintsuk, F. Bernard. Phys. Scr. T 159 (2014) 014034.

117. J. Ma, J. Zhang, W. Liu, Z. Shen. J. Nucl. Mater. 438 (2013) 199.

118. Z. Gao, G. Viola, B. Milsom, I. Whitaker, H. Yan, M.J. Reece. Metall. Mater. Trans. B 43 (2012) 1608.

119. K. Wang, X.P. Wang, R. Liu, T. Hao, T. Zhang, C.S. Liu, Q.F. Fang, J. Nucl. Mater. 431 (2012) 206.

120. J. Hyesook, H. Chulwoong, K. Byungmoon, K. Dohyang, C. Hanshin, Rev. Adv. Mater. Sci. 28 (2011) 200.

121. A. Mondal, A. Upadhyaya, D. Agrawal, Int. J. Refract. Met. H 28 (2010) 597.

122. A. Moitra, S. Kim, S.-G. Kim, S.J. Park, R.M. German, M.F. Horstemeyer, Acta Mater. 58 (2010) 3939.

123. R.D. Conner, R.B. Dandliker, W.L. Johnson, Acta Mater. 46 (1998) 6089.

124. G. Xie, D.V. Louzguine-Luzgin, H. Kimura, A. Inoue, Intermetall. 18 (2010) 851.

\section{Acknowledgements}

This work was supported by a grant from the Defense Threat Reduction Agency (DTRA) under award number HDTRA-1-11-1-0067. The funder did not participate in study design; in the collection, analysis and interpretation of data; in the writing of the report; and in the decision to submit the article for publication.

\section{Author Contributions}


J.P.K. and O.A.G. conceived the study, analyzed the results, and wrote the manuscript, J.P.K. and S.M.F. performed the sintering experiments, K.S. performed the differential scanning calorimetry experiments, E.N. performed the transmission electron microscopy experiments, V.E. and A.M.H. participated in the analyses of results. All authors have reviewed and approved the manuscript.

\section{Additional Information}

The authors declare no competing financial interests.

\section{Figure Legends}

Figure 1. (a) Secondary electron image of SAM2X5 powder, (b) back-scattered electron (BSE) image of cross-sectioned SAM2X5 particles, (c) BSE image of a large crystalline particle with an internal pore embedded in a dense SAM2X5 specimen, (d) BSE image of ductile inclusion embedded in a dense SAM2X5 specimen, (e) BSE image of an inclusion embedded in a dense SAM2X5 specimen, (f) BSE image of particle with an internal pore embedded in a dense SAM2X5 specimen, (g) energy dispersive spectrum (EDS) of Ni-rich ductile particles embedded in a dense SAM2X5 specimen, and (h) EDS spectrum of Mo-rich inclusions embedded in a Modepleted inclusion within a dense SAM2X5 specimen.

Figure 2. Schematic of temperature and pressure profiles used to systematically alter pressing rate during spark plasma sintering. Changing sintering temperature (compare A to B and corresponding $\mathrm{A}^{\prime}$ and $\mathrm{B}^{\prime}$ stress profiles) or changing heating rate (compare $\mathrm{B}$ to $\mathrm{C}$ and corresponding $\mathrm{B}^{\prime}$ and $\mathrm{C}^{\prime}$ 'stress profiles) results in changes to the pressing rate.

Figure 3. (a) Pressing ram displacement rate during when consolidating SAM2X5 powder with different heating rates. (b) SAM2X5 density as a function of applied pressing rate during spark plasma sintering for either a constant heating rate and temperatures of 900-960 K or with constant sintering temperature and heating rates of $50-500 \mathrm{~K} / \mathrm{min}$. (c) SAM2X5 densification map illustrating the relationship between sintering temperature $\left(\mathrm{T}_{\mathrm{s}}\right)$, density $(\rho)$, and heating rate $(\phi)$ during spark plasma sintering.

Figure 4. Differential scanning calorimetry curves collected using different heating rates with insets having truncated scales to demonstrate more detail, such as four distinct exothermic events labeled $\mathrm{T}_{\mathrm{x} 1}, \mathrm{~T}_{\mathrm{x} 2}, \mathrm{~T}_{\mathrm{x} 3}$, and $\mathrm{T}_{\mathrm{x} 4}$ on the curve corresponding to a heating rate of $20 \mathrm{~K} / \mathrm{min}$.

Figure 5. Plot generated from peak exothermic temperatures with varying heating rate $\phi$ (10$100 \mathrm{~K} / \mathrm{min}$ ) and the corresponding slopes used to calculate activation energies via the Kissinger method [80].

Figure 6. (a) X-ray diffraction (XRD) patterns demonstrating initial devitrification of SAM2X5 at sintering temperatures of 820 and $880 \mathrm{~K}$, (b) patterns demonstrating secondary devitrification at sintering temperatures of 910 and $960 \mathrm{~K}$, and (c) patterns demonstrating tertiary devitrification observed at longer holding times (heating rate of $100 \mathrm{~K} / \mathrm{min}$ and sintering temperature of $960 \mathrm{~K}$ ). 
(d) TTT diagram generated using a heating rate of $100 \mathrm{~K} / \mathrm{min}$ demonstrating the boundaries for the onset of the second and third structural transformations with respect to sintering temperature and time (black curves) and contours corresponding the full-width at half-maximum of the primary XRD peak. Onset and peak temperatures, $\mathrm{T}_{\mathrm{oi}}$ and $\mathrm{T}_{\mathrm{xi}}$, of the structural transformations as determined by DSC are also included on the right.

Figure 7. (a) Back-scattered electron (BSE) image of partially devitrified SAM $2 X 5$ composite, (b) transmission electron microscope (TEM) image of SAM2X5 composite, (c) BSE image of Xray amorphous SAM2X5-XS1 composite, (d) TEM image of SAM2X5-XS1 composite, (e) isolated single crystal embedded in amorphous matrix of SAM2X5 composite, and (f) cluster of crystals embedded in amorphous matrix of SAM2X5 composite.

Figure 8. (a) Back-scattered electron (BSE) image of W agglomerated in a SAM2X5-4NW composite and (b) BSE image of matrix cracking in a SAM2X5-10MW4 composite.

Figure 9. (a) Density of SAM2X5 composites with different particle sizes as a function of W volume fraction, (b) X-ray diffraction patterns of SAM2X5, SAM2X5-2NW, and SAM2X530MW3 composites with an inset having a truncated y-axis to give more detail on the behavior of the SAM2X5 matrix phase, and (c) transmission electron microscope image of SAM2X5 matrix/W interface in SAM2X5-30MW3 composite.

Figure 10. Secondary electron (SE) images of (a) SAM2X5-2NW, (b) SAM2X5-10MW1, (c) SAM2X5-20MW2, and (d) SAM2X5-30MW3, (e) transmission electron microscope image of W/W interfaces in a SAM2X5-30MW3 composite, and (f) SE image of SAM2X5-30MT composite. 

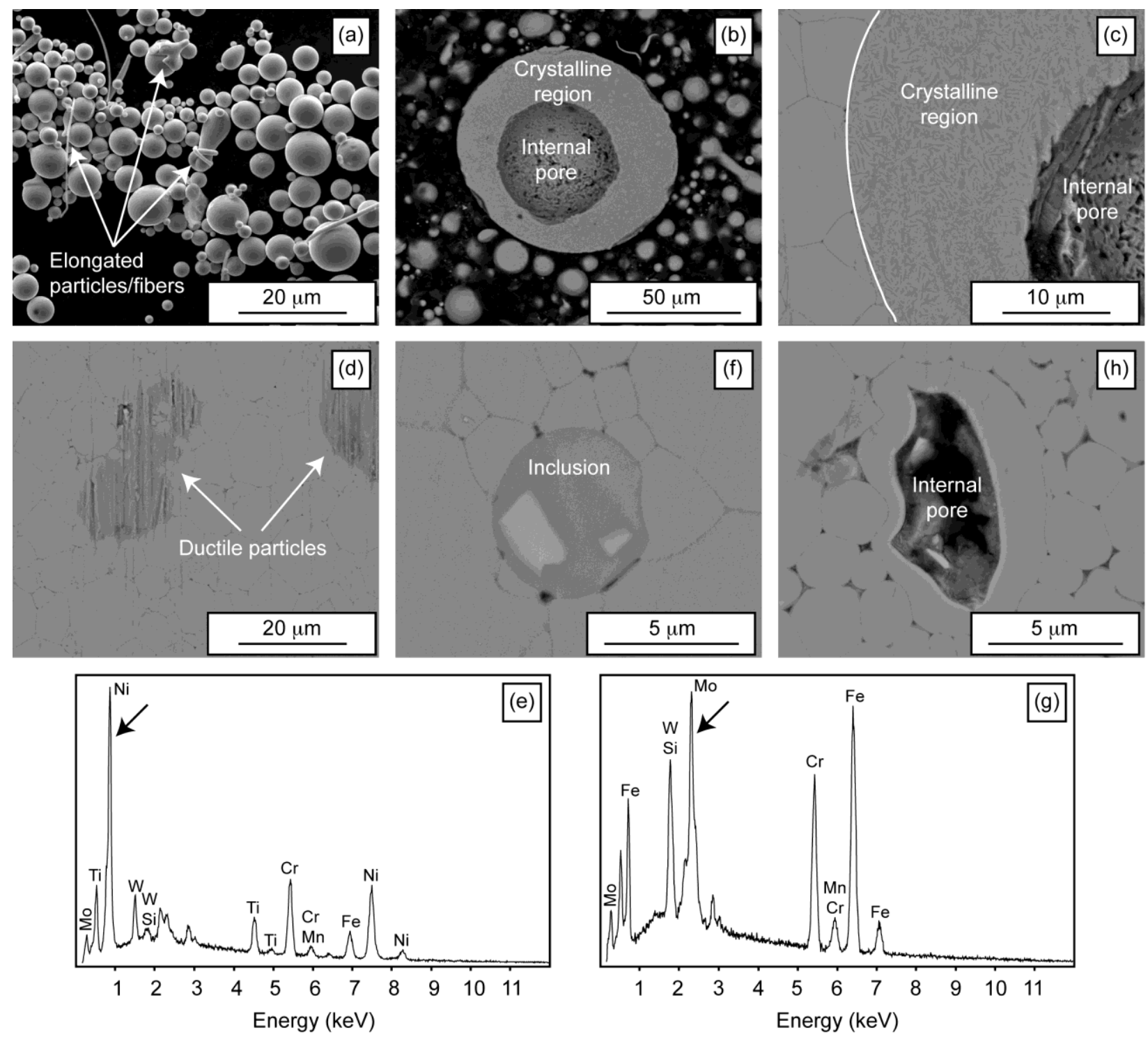

Figure 1 


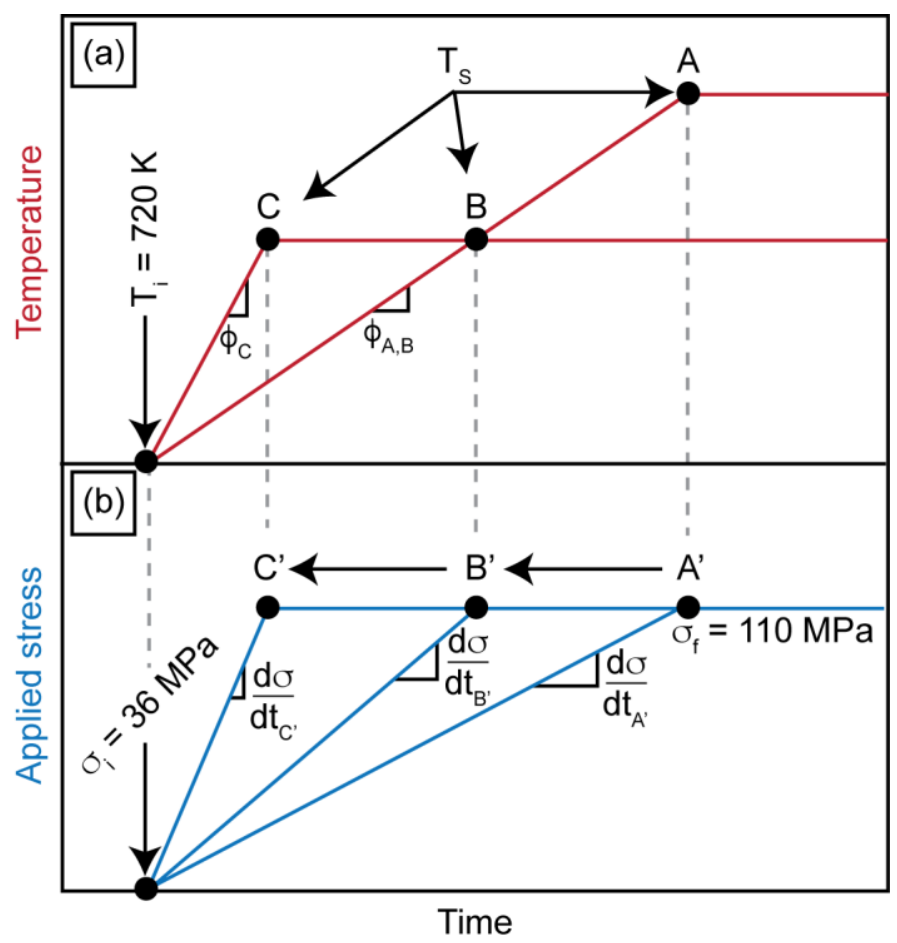

Figure 2 

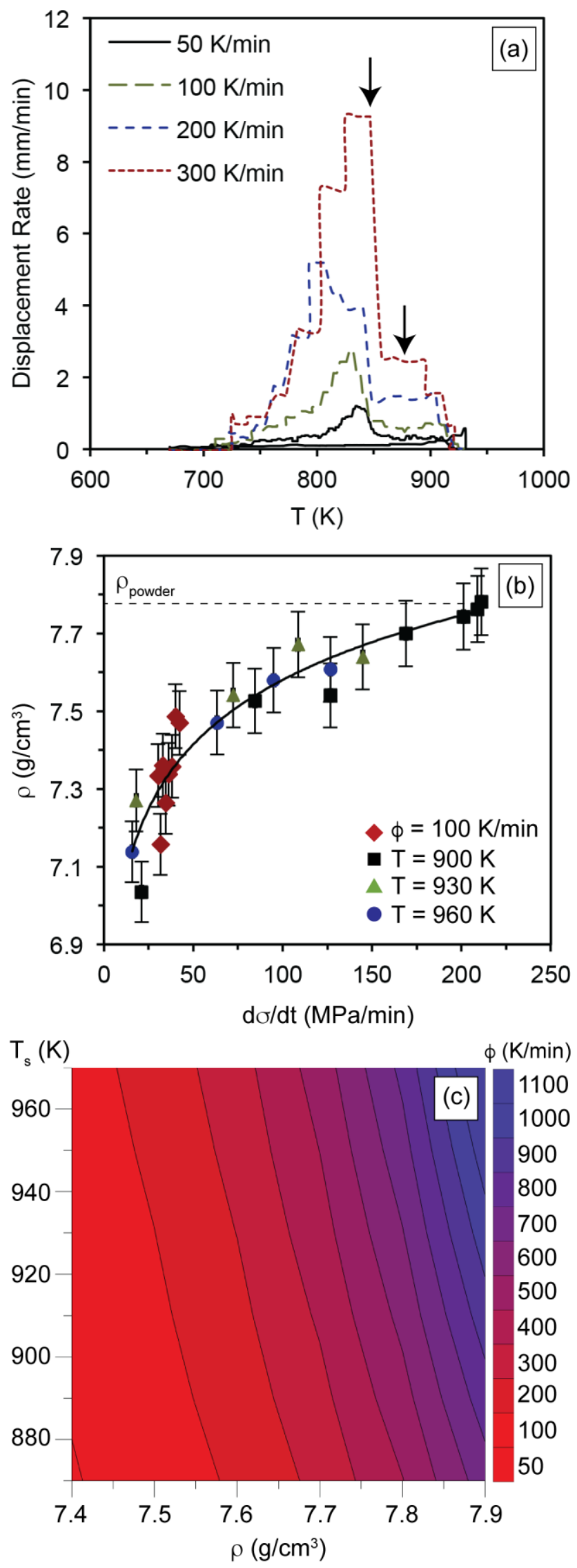

Figure 3 


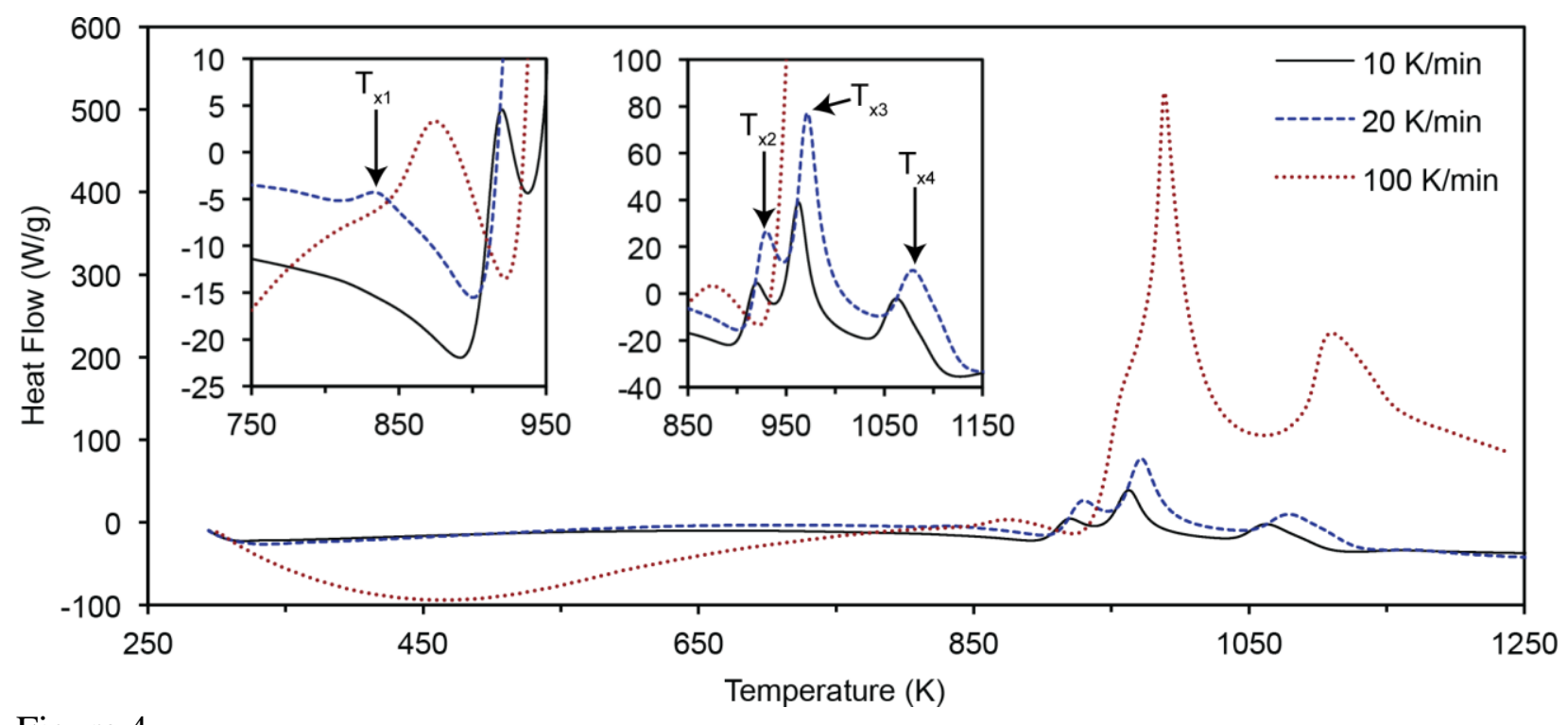

Figure 4 


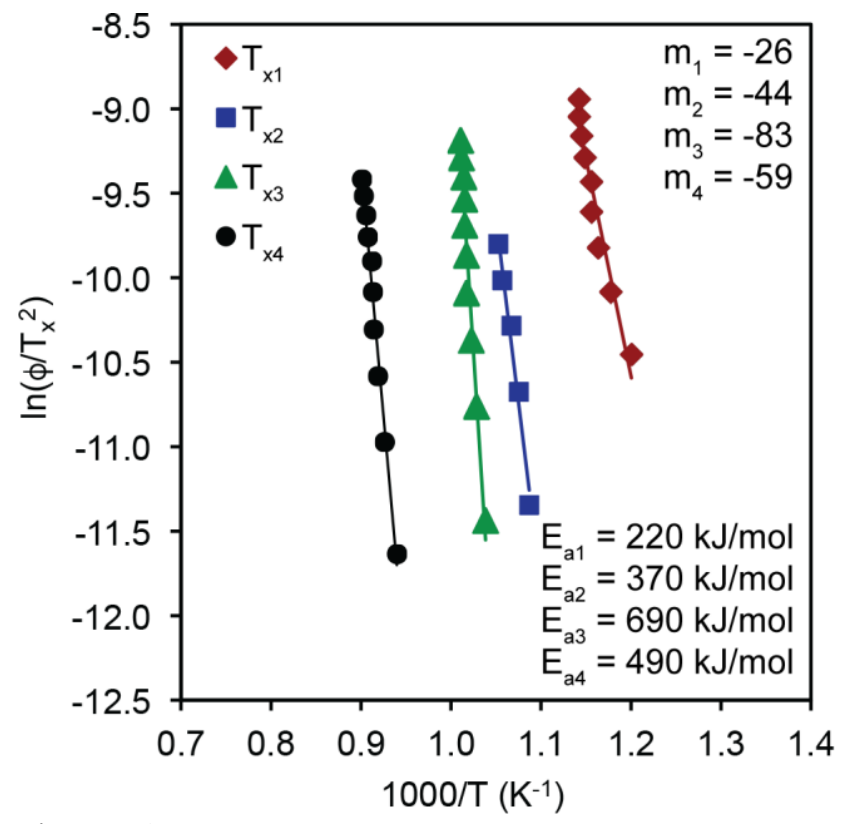

Figure 5 

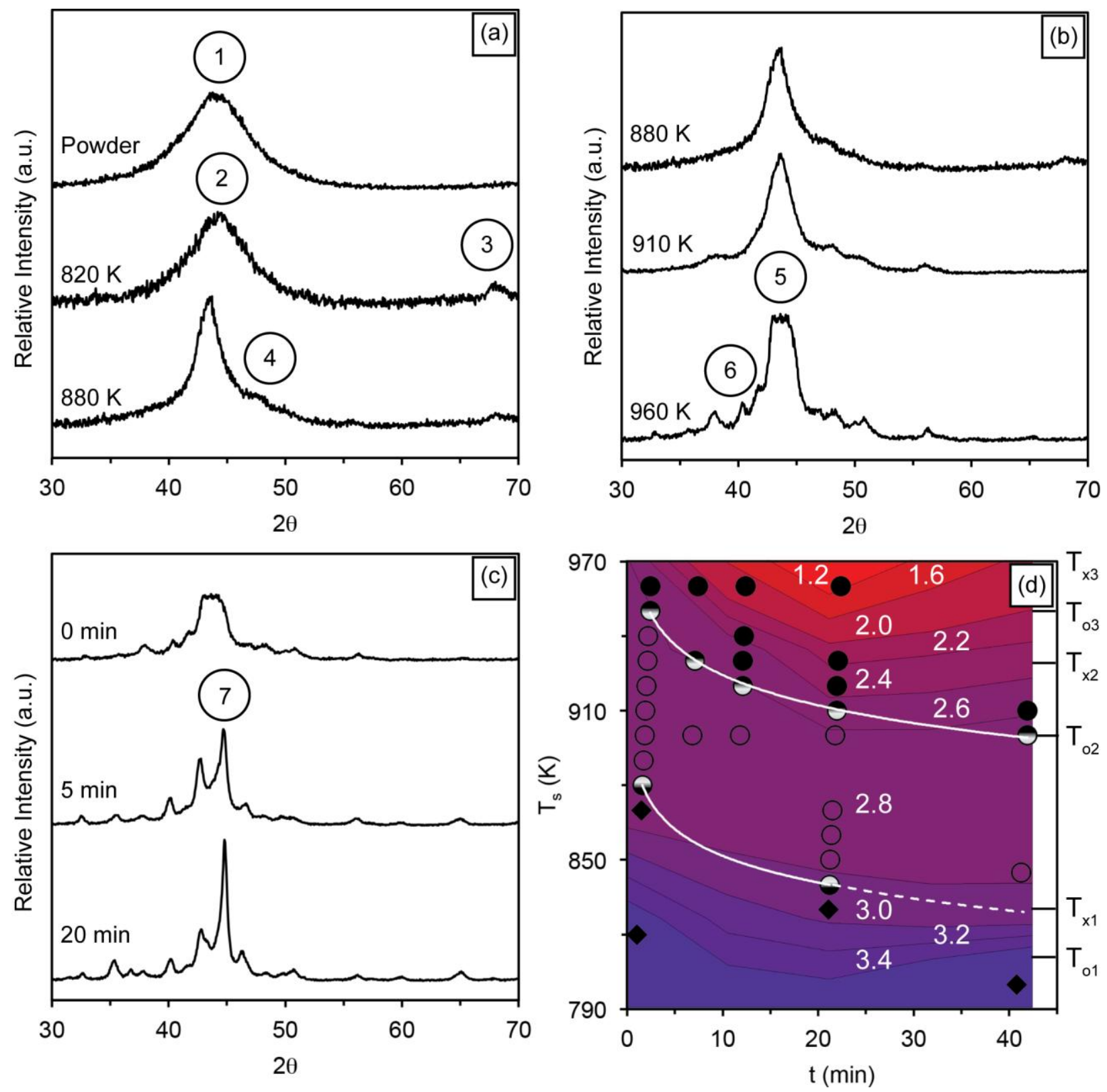

Figure 6 

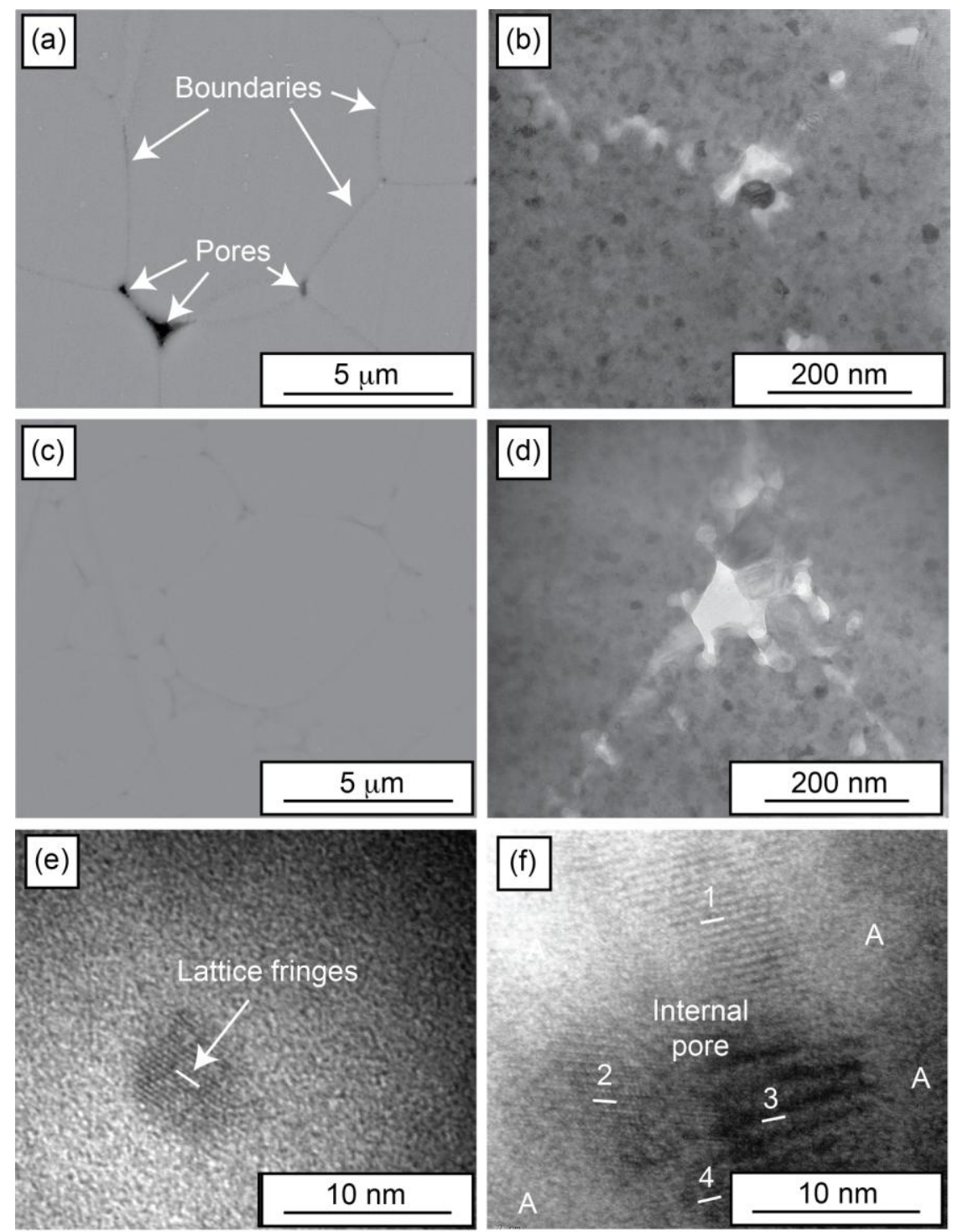

Figure 7 

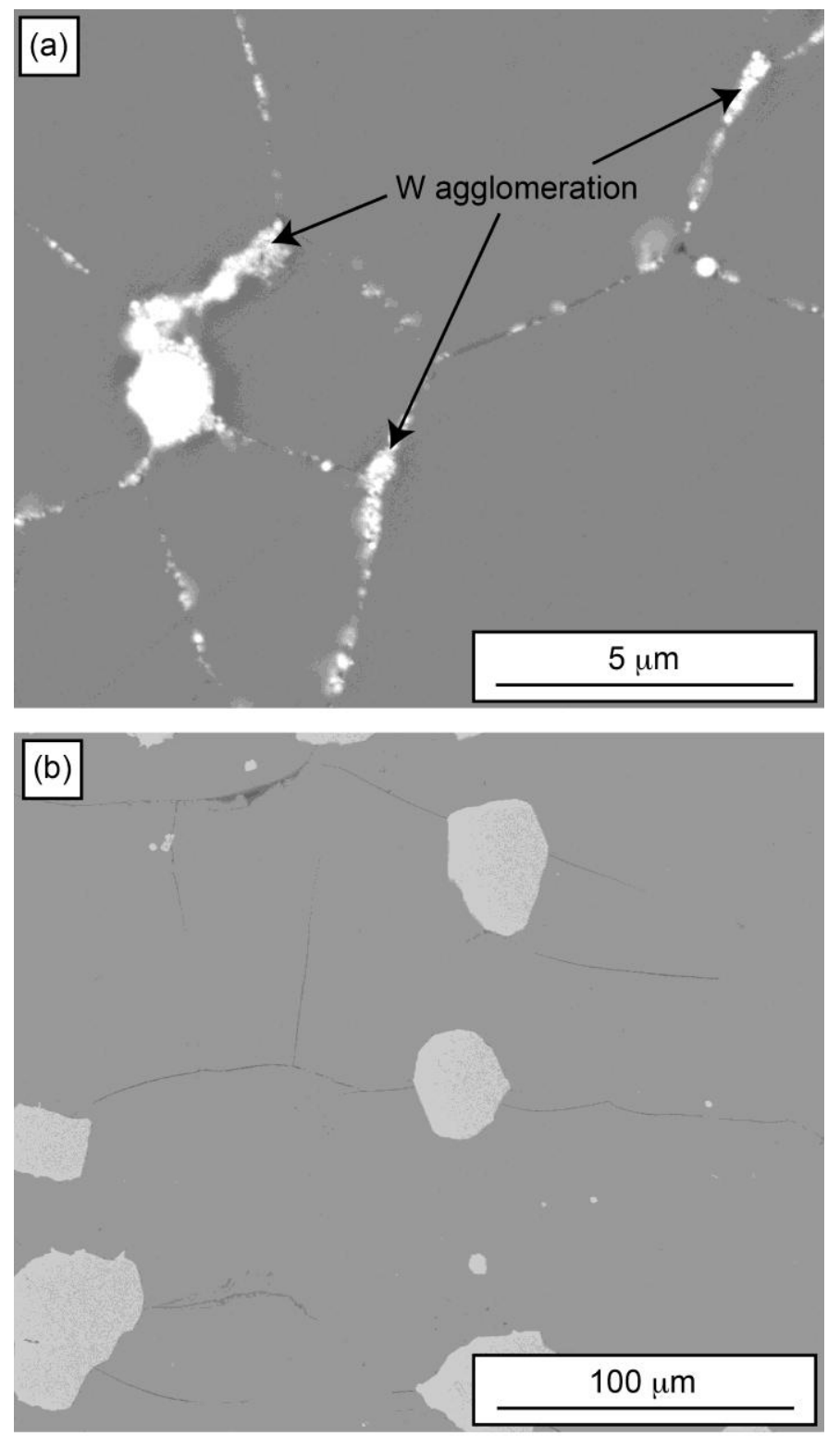

Figure 8 

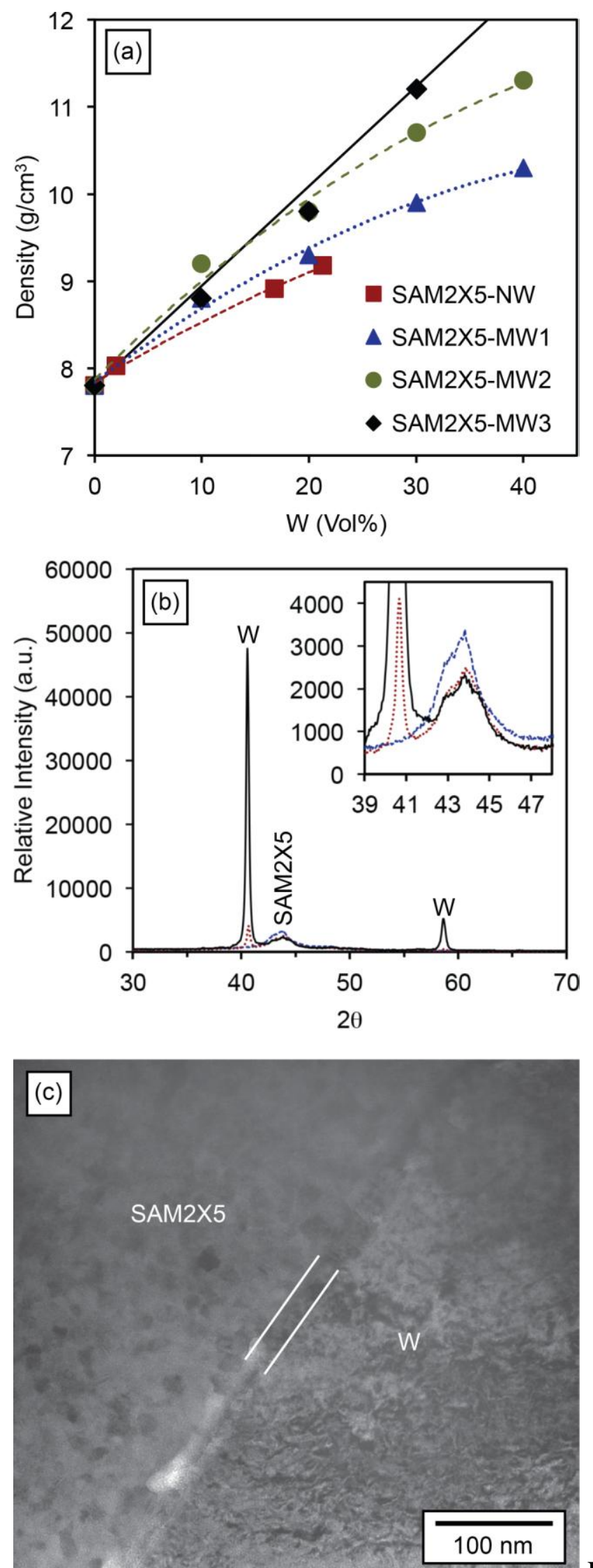

Figure 9 

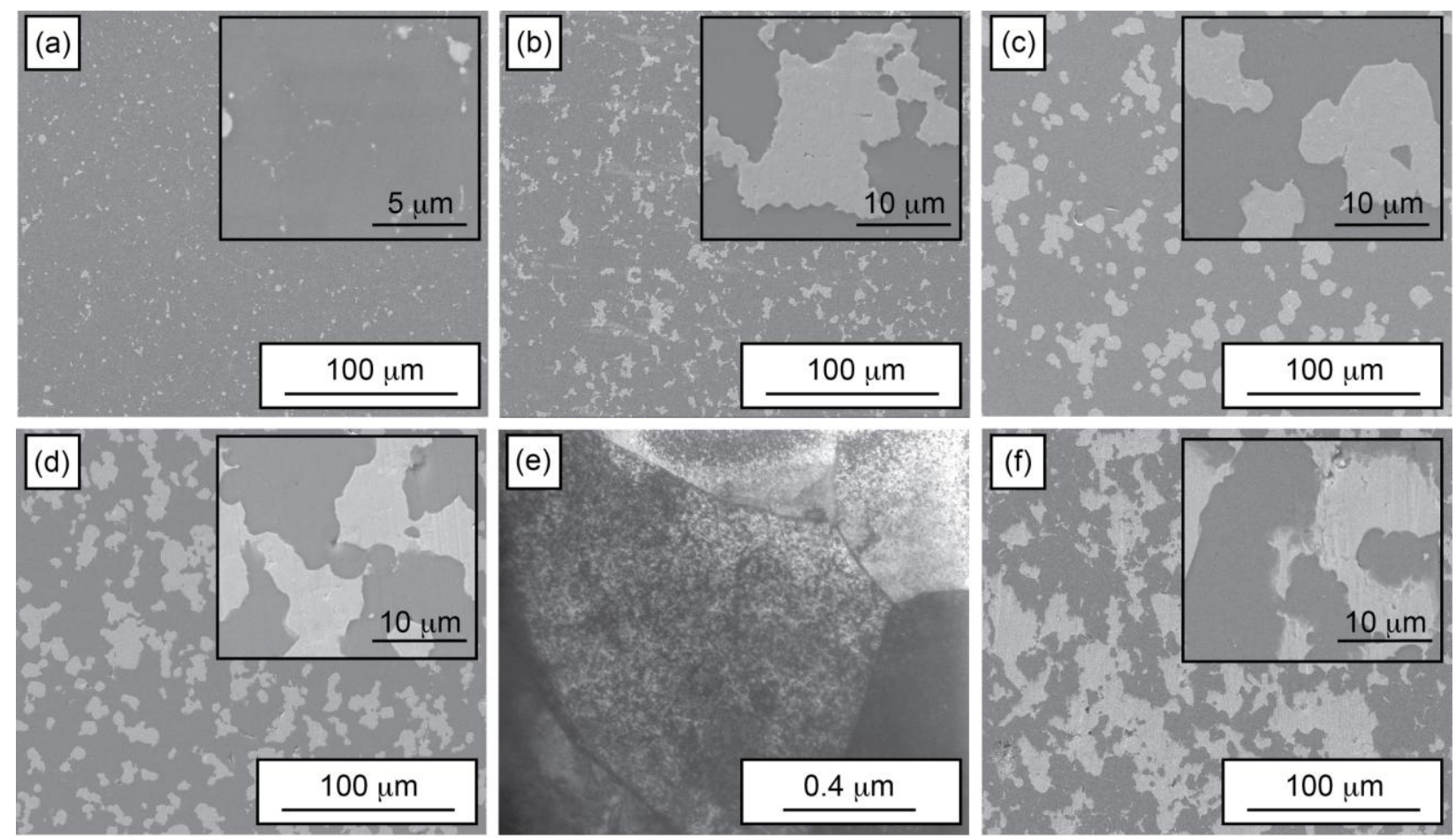

Figure 10 


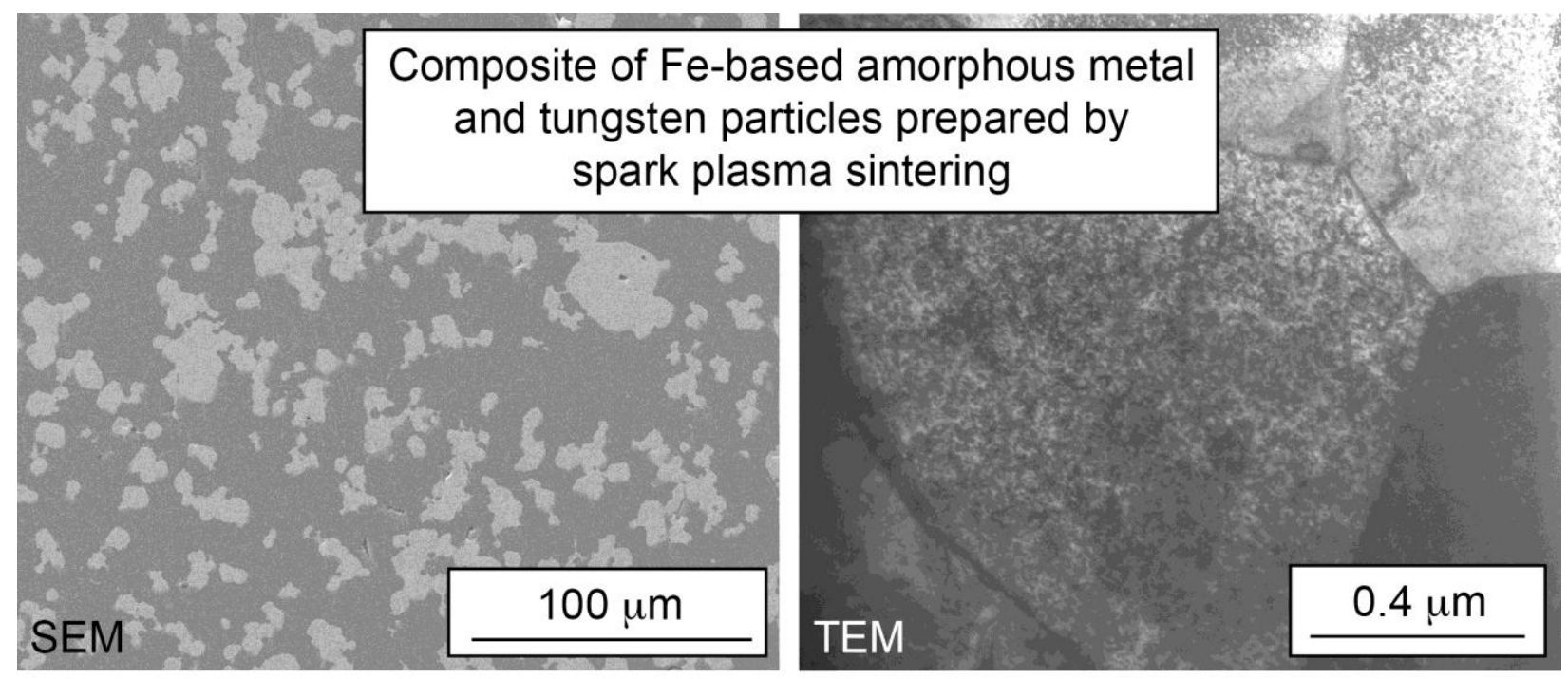

Graphical Abstract 